\title{
Cachexia-associated adipose loss induced by tumor-secreted leukemia inhibitory factor is counterbalanced by decreased leptin
}

\author{
Gurpreet K. Arora, ${ }^{1,2}$ Arun Gupta, ${ }^{2}$ Sriram Narayanan, ${ }^{2}$ Tong Guo, ${ }^{1}$ Puneeth Iyengar, ${ }^{2,3}$ \\ and Rodney E. Infante ${ }^{1,4,5}$ \\ 'Department of Molecular Genetics, ${ }^{2}$ Department of Radiation Oncology, ${ }^{3} \mathrm{H}$ arold C. Simmons Comprehensive Cancer \\ Center, ${ }^{4}$ Department of Internal Medicine, and ${ }^{5}$ Center for Human Nutrition, University of Texas (UT) Southwestern \\ Medical Center, Dallas, Texas, USA.
}

\begin{abstract}
Cachexia syndrome consists of adipose and muscle loss, often despite normal food intake. We hypothesized that cachexia-associated adipose wasting is driven in part by tumor humoral factors that induce adipocyte lipolysis. We developed an assay to purify secreted factors from a cachexiainducing colon cancer line that increases lipolysis in adipocytes and identified leukemia inhibitory factor (LIF) by mass spectrometry. Recombinant LIF induced lipolysis in vitro. Peripheral LIF administered to mice caused $>50 \%$ loss of adipose tissue and $>10 \%$ reduction in body weight despite only transient hypophagia due to decreasing leptin. LIF-injected mice lacking leptin (ob/ob) resulted in persistent hypophagia and loss of adipose tissue and body weight. LIF's peripheral role of initiating lipolysis in adipose loss was confirmed in pair-fed ob/ob mouse studies. Our studies demonstrate that (a) LIF is a tumor-secreted factor that promotes cachexia-like adipose loss when administered peripherally, (b) LIF directly induces adipocyte lipolysis, (c) LIF has the ability to sustain adipose and body weight loss through an equal combination of peripheral and central contributions, and (d) LIF's central effect is counterbalanced by decreased leptin signaling, providing insight into cachexia's wasting, despite normophagia.
\end{abstract}

Authorship note: GKA and AG contributed equally to this work.

Conflict of interest: The authors have declared that no conflict of interest exists.

Submitted: March 21, 2018

Accepted: June 19, 2018

Published: July 25, 2018

Reference information: JCI Insight. 2018;3(14):e121221. https://doi.org/10.1172/jci. insight.121221.

\section{Introduction}

Cachexia (CX) syndrome consists of loss of adipose and muscle mass, often despite little change in caloric intake (1). This paradox of weight loss in the setting of normophagia has confounded researchers and clinicians. CX occurs in chronic inflammatory states including infection, rheumatologic conditions, and heart failure and in $\sim 50 \%$ of cancer patients $(2,3)$. Most preclinical and clinical trials to reverse CX, including targeting of the immune system (anti-TNF $\alpha$ and anti-IL-6), appetite stimulation (agonists of ghrelin receptor and cannabinoid receptor), and muscle regeneration (androgen receptor agonist and myostatin), have failed (4). Previous efforts to suppress CX have focused on muscle atrophy rather than changes in adipose tissue (5). However, enhanced lipolysis has also been identified in cachectic cancer patients (6-8). Blocking lipolysis through the genetic ablation of adipose triglyceride lipase (ATGL) in mice administered cancer cells that induce CX had complete inhibition of adipose tissue loss compared with littermate controls (8). Partial blocking of adipose tissue loss was observed in mice with genetic ablation of hormone sensitive lipase (HSL).

Obesity leads to greater mortality and is a risk factor for other diseases, including diabetes and cancer $(9$, 10). Similar to $C X$, obesity also lacks sustainable treatment options. Empirically, obese patients with $C X$ frequently have improvement in insulin resistance, joint pain, sleep apnea, and nonalcoholic fatty liver disease as they lose weight. Therefore, identification of factors and mechanisms that underlie CX may lead to new treatments for CX patients and may also provide insights for treatment of obesity and its related complications.

To identify factors that mediate CX, we developed an in vitro lipolysis assay to screen for proteins that are involved in cancer CX-associated adipose tissue loss. Using a cancer cell line that causes CX in vivo, we biochemically purified secretory factors that enhance lipolytic activity in adipocytes and identified leukemia inhibitory factor (LIF). LIF is a member of the IL-6 cytokine family, which includes 
cardiotrophin-1, oncostatin $\mathrm{M}$, and ciliary neurotrophic factor (CNTF), among others (11). LIF interacts through its cognate receptor on cell surfaces, LIFR- $\alpha$, which forms a heterodimer with its coreceptor subunit gp130 to activate the JAK/STAT pathway (12). LIF regulates growth and differentiation of a wide variety of cell types and is involved in processes as disparate as inflammation, neural development, hematopoiesis, embryogenesis, and fertilization (13-15).

The earliest studies evaluating LIF in animals were intended to assess its effect on hematopoiesis. Interestingly, an unexpected off-target effect of LIF was a decrease in body weight (16). Intracerebroventricular injections of LIF adenovirus into mice also decreased body weight, with modest changes in food intake (17). Recently, LIF has been linked to muscle wasting in cancer CX (18). CNTF, another member of the IL-6 family, also decreased food intake and subsequent body weight in rodents $(19,20)$. CNTF was evaluated in a large phase 3 randomized trial in the context of amyotrophic lateral sclerosis as a CNS promoter of neuronal regeneration and function. An unexpected off-target effect of CNTF in this trial was significant weight loss $(21,22)$, further implicating this family in CX.

Here, we identified LIF as a factor secreted from cancer cells that induced lipolysis. Immunodepletion of LIF from partially purified medium removed lipolysis activity. Recombinant LIF (rLIF) added to cultured adipocytes confirmed that LIF induced lipolysis. LIF-induced lipolysis was dependent on its receptor, LIFR- $\alpha$, and coreceptor, gp130, which activated the STAT pathways and, ultimately, ATGL. rLIF injected into WT and genetically obese mouse models resulted in significant loss of adipose tissue. Interestingly, WT mice with an intact leptin axis chronically administered rLIF showed a decrease in body weight and adipose tissue, with little change in overall food intake. However, these mice demonstrated an early transient hypophagic state that returned to normophagia as leptin levels decreased. Persistent rLIF-induced hypophagia could be maintained in these mice by coadministration of recombinant leptin (rleptin), resulting in further body weight and adipose loss. Administration of rLIF to 2 hyperphagic murine models, leptin deficient $(o b / o b)$ and leptin signaling-deficient $(d b / d b)$ mice, showed a persistent decrease in food intake. Importantly, rLIF administration to $o b / o b$ mice resulted in loss of fat mass and body weight compared with PBS controls that were pair fed, demonstrating that LIF has an effect independent of changes in food intake and leptin levels. These studies suggest that LIF has both a direct peripheral contribution $(50 \%-60 \%)$ and an independent central contribution (40\%-50\%) promoting transient hypophagia, which leads to adipose tissue loss followed by leptin counterregulation, ultimately providing an explanation for normal food intake in CX.

\section{Results}

CX-inducing C26c20 cells secrete factors that increase adipocyte lipolysis. C26 represents an undifferentiated murine adenocarcinoma cell line created by chemical carcinogen induction in Balb/c mice followed by serial passage of resulting tumors in syngeneic mice. These tumor-bearing mice develop loss of fat and lean body mass (23). A clone of this cell line, C26c20, increased the amount of weight loss, adipose tissue loss, and muscle atrophy when injected s.c. into Balb/c mice (24). Considering that human colon adenocarcinoma is associated with CX (25), we reasoned that the C26c20 murine colon adenocarcinoma cell line is a potential model to identify secreted factors capable of inducing loss of fat mass. To validate this cell line's potential to induce CX, we injected C26c20 cells or PBS in the right hind leg of syngeneic Balb/c mice. As the C26c20 tumor increased in size (Supplemental Figure 1A; supplemental material available online with this article; https://doi.org/10.1172/jci.insight.121221DS1), both the body weight (Supplemental Figure 1B) and adipose mass (Supplemental Figure 1D) decreased compared with mice injected with PBS. Lean mass (Supplemental Figure 1E) and food intake (Supplemental Figure 1C) showed no differences in C26c20-injected mice compared with PBS-injected mice.

To test if the C26c20 cells had an intrinsic ability to induce adipocyte lipolysis, we developed an in vitro model. C26c20 cells were incubated for 20 hours in culture medium that did not contain phenol red or FBS. As a control, we used MC-38 cells, an undifferentiated murine colon adenocarcinoma line made similarly to the C26c20 line but one that does not induce the CX phenotype in allotransplant mouse models (26). Conditioned medium from the C26c20 and MC-38 cells was subsequently placed on differentiated adipocytes, and the amount of glycerol released into the medium was quantified. Glycerol release into the medium is a marker for triglyceride lipolysis in adipocytes (27). As shown in Figure 1A, adipocytes exposed to conditioned medium containing C26c20 tumor secretory factors had about 6-fold more glycerol secreted into the medium compared with adipocytes exposed to conditioned medium from control MC-38 cells. 
A

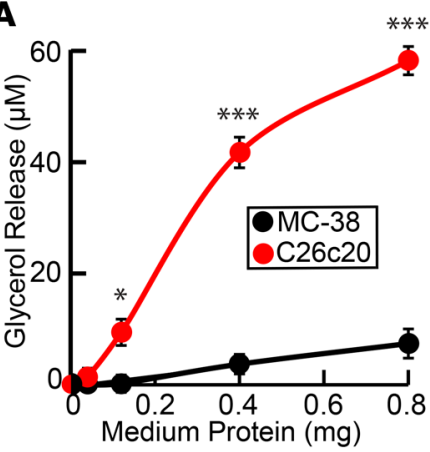

C

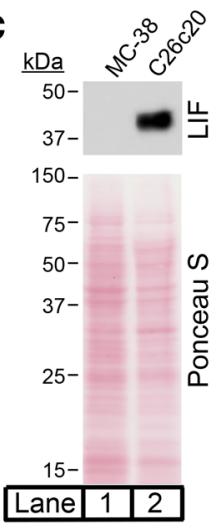

B
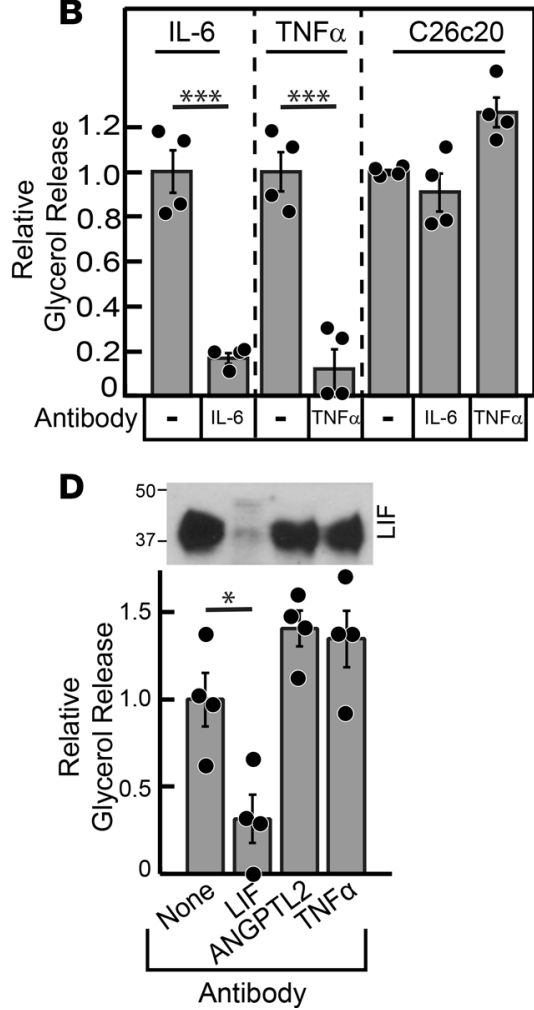

Figure 1. Biochemical characterization of lipolysis activity from C26c20 cell line medium. (A and B) Characterization of cancer cell line medium-induced adipocyte lipolysis. Medium was collected, processed, and protein quantified from C26c20 or MC-38 cells as described in Methods. Differentiated adipocytes in a 12-well format were treated with $1.5 \mathrm{ml}$ of medium E with the indicated amount of $\mathrm{C} 26 \mathrm{c} 20$ or MC-38 medium (A) or $150 \mathrm{ng}$ of recombinant IL-6, $150 \mathrm{ng}$ of recombinant TNF $\alpha$, or either $1.8 \mathrm{mg}$ or $3.1 \mathrm{mg}$ C26c20 medium in the absence or presence of $4.5 \mu \mathrm{g}$ of the indicated antibody (B). After incubation for 20 hours at $37^{\circ} \mathrm{C}$, medium was collected and glycerol concentration was measured using the adipocyte lipolysis assay described in Methods. Data are shown as mean \pm SEM (A) or dot plots with bars representing mean \pm SEM (B) of 3 or 4 (A and B, respectively) experiments and represents the absolute increase of medium glycerol concentration over background $(\mathbf{A})$ or as the relative change in medium glycerol concentration compared with conditions containing the indicated protein without antibody (B) (IL-6, 54 and $19 \mu \mathrm{M}$; TNF $\alpha, 25$ and $36 \mu \mathrm{M} ; \mathrm{C} 26 \mathrm{c} 20$ medium, 37 and $20 \mu \mathrm{M}$ ). (C) Leukemia inhibitory factor (LIF) expression in medium of cancer cells. Medium (15 ml) from C26c20 and MC-38 was concentrated to a final volume of $150 \mu$ l using a $10 \mathrm{kDa}$ MW cut-off Amicon Ultra centrifugal filter, and protein was quantified using a bicinchoninic acid kit. Protein $(20 \mu \mathrm{g})$ was subjected to IB analysis with anti-LIF and Ponceau $\mathrm{S}$ stain described in Methods. (D) Immunodepletion of LIF from partially purified C26c20 medium. C26c20 medium was partially purified as described in Methods. Approximately $14 \mu \mathrm{g}$ of the elution fractions containing lipolysis activity in Step 1 of the partial purification of C26c20 medium in $300 \mu$ of buffer A with $0.2 \%$ BSA was subjected to immunodepletion described in Methods using $2 \mu \mathrm{g}$ of the indicated antibody. The supernatant fraction from the immunodepletion was collected, and $30 \mu \mathrm{l}$ was subjected to IB analysis with the indicated antibody and $20 \mu \mathrm{l}$ subjected to the adipocyte lipolysis assay described in Methods. Data are shown as dot plots with bars representing mean \pm SEM of 4 experiments and is represented as the relative change in medium glycerol concentration compared with conditions containing the indicated protein without antibody $(33$ and $64 \mu \mathrm{M}) .{ }^{*} P<0.05$ and ${ }^{* * *} P<0.001$ based on Student's $t$ test.

IL-6 and TNF $\alpha$ are secreted factors known to induce lipolysis. To rule out these proteins as lipolytic factors in the medium, we used antibodies directed against IL- 6 and TNF $\alpha$ to neutralize their activity. Commercially available recombinant proteins and antibodies were obtained for IL- 6 and TNF $\alpha$. The antibodies against IL- 6 and TNF $\alpha$ neutralized the lipolysis activities of their respective recombinant proteins (Figure $1 \mathrm{~B}$, left and middle panels). However, these antibodies were unable to neutralize the lipolysis activity induced by medium of $\mathrm{C} 26 \mathrm{c} 20$ cells (Figure 1B, right panel).

Identification of LIF as a secreted factor from C26c20 cells that induces adipocyte lipolysis. To identify the proteins that mediated lipolysis in C26c20 conditioned medium, we carried out a biochemical purification using the lipolysis assay described in Methods. The overall scheme of the enrichment of lipolysis activity from the CX tumor-conditioned medium is described in Supplemental Table 1. Lipolysis activity was partially purified $>250$-fold with a $2 \%$ recovery in 2 separate purifications. The partially purified complex fraction from each of 
the separate purifications was subjected to mass spectrometry analysis, yielding peptides from 118 significant unique proteins that were present in both purifications. Only 26 of these proteins contained a signal sequence, an expected characteristic of secreted factors. Of these signal sequence-containing proteins, LIF was among the top 10 proteins with the highest peptide spectra matches elicited from mass spectrometry analysis (Supplemental Table 2). We focused on LIF from this list for further studies, owing to its previous association with muscle wasting in cancer CX (18) and body weight changes when expressed in or administered to animals $(16,17)$. Furthermore, LIF's RNA expression is highest in human cancers (lung, gastrointestinal, and renal) that are associated with cancer CX (Supplemental Figure 2).

To be considered a relevant driver of cancer CX-induced lipolysis, we would expect LIF expression to be increased primarily in CX-inducing cancer cell lines. Medium from the CX- (C26c20) and non-CXinducing (MC-38) cell lines, which demonstrated a significant difference in lipolysis activity (Figure 1A), were subjected to SDS/PAGE followed by immunoblot (IB) analysis of LIF. There was a greater than 10 -fold increase in LIF protein in the C26c20 CX medium versus the MC-38 non-CX control medium (Figure 1C, upper panel, lane 1 vs. lane 2) with similar amounts of total protein found in medium of both cell lines as judged by Ponceau S stain of the membrane (Figure 1C, bottom panel, lane 1 vs. lane 2). When partially purified C26c20 medium was immunodepleted of LIF, lipolysis activity was decreased to background levels (Figure 1D), consistent with the hypothesis that LIF was responsible for the lipolysis activity in our partially purified material.

To confirm that LIF induced lipolysis, we produced recombinant murine LIF with an N-terminal His6 tag followed by a TEV protease site in bacteria. As described in Methods, WT rLIF was purified using a combination of nickel and size-exclusion chromatography before and after the removal of the $\mathrm{N}$-terminal His6 tag by TEV protease treatment. Gel-filtration chromatography (Figure 2A) of purified rLIF eluted as a single sharp peak at its expected monomer molecular weight (MW) ( 20 kDa), and its homogeneity was confirmed by Coomassie staining (Figure 2A, inset). Endotoxin was removed below $0.05 \mathrm{EU} / \mu \mathrm{g}$ protein from purified recombinant protein by Polymyxin B chromatography. Previous efforts identified a point mutation (K159A) in LIF that abolishes LIF's interaction with its receptor (28). rLIF K159A has a >100fold decrease in binding affinity to LIFR- $\alpha$ and activation of the JAK/STAT pathway compared with WT LIF (28); therefore, we compared the activity of LIF and LIF K159A to induce lipolysis. The mutant LIF (rLIF K159A) was purified using the same expression and purification scheme as for WT rLIF. Purified rLIF K159A eluted as a single sharp peak, similar to WT rLIF on gel-filtration chromatography (Figure 2A), and its homogeneity was confirmed by Coomassie staining (Figure 2A, inset). Using the tissue culture adipocyte lipolysis assay, we tested both purified recombinant versions of LIF for their ability to stimulate lipolysis. As shown in Figure 2B, in vitro adipocyte lipolysis activity with WT rLIF was increased over background by $\sim 5$-fold compared with mutant rLIF K159A.

LIF induces adipocyte ATGL-mediated lipolysis through GP130 and JAK/STAT activation. To further interrogate LIF's mechanism for induction of lipolysis, we tested LIF's capacity to signal through its canonical pathway activated in other tissues. LIF binds to the LIFR- $\alpha$ receptor and gp130 coreceptor, causing activation of the JAK/STAT pathway in multiple tissues, including muscle and endometrium $(18,29)$. To confirm that LIF uses its typical coreceptor gp130 to induce lipolysis, we attempted to neutralize LIF-induced lipolysis with antibody against gp130. As shown in Figure 2E, LIF's ability to induce lipolysis was blocked with antibodies to LIF itself or to the gp130 coreceptor, but not with IL-6 antibody. Further downstream, we interrogated JAK/STAT activation. The adipocytes described in Figure $2 \mathrm{~B}$ were processed for IB analysis. As shown in Figure 2C, treatment of adipocytes with increasing concentrations of WT rLIF (lanes 2-4) showed a corresponding increase in the phosphorylation of STAT1 (third panel) and STAT3 (first panel), while rLIF K159A (lanes 5-7) had no effect on the phosphorylation of these proteins. Total STAT1 (fourth panel) and STAT3 (second panel) protein levels remained constant among the groups.

In adipocytes, triglycerides are sequentially hydrolyzed by ATGL, HSL, and monoacylglycerol lipase (MGL). Data from others suggested that CX-induced lipolysis requires ATGL activity (8). To determine if ATGL is involved in LIF-induced lipolysis, we incubated adipocytes with rLIF or isoproterenol in the absence or presence of increasing concentrations of the ATGL inhibitor Atglistatin. As shown in Figure 2D, Atglistatin treatment of adipocytes only inhibited rLIF-induced lipolysis but not lipolysis induced by isoproterenol.

LIF induces loss of adipose tissue and body weight without persistent alteration in food intake. To determine whether LIF induces lipolysis and a CX-like phenotype in vivo, we administered rLIF to mice syngeneic to the C26c20 tumor line, Balb/c. Mice were injected either with PBS, rLIF, or rLIF K159A at a dose 

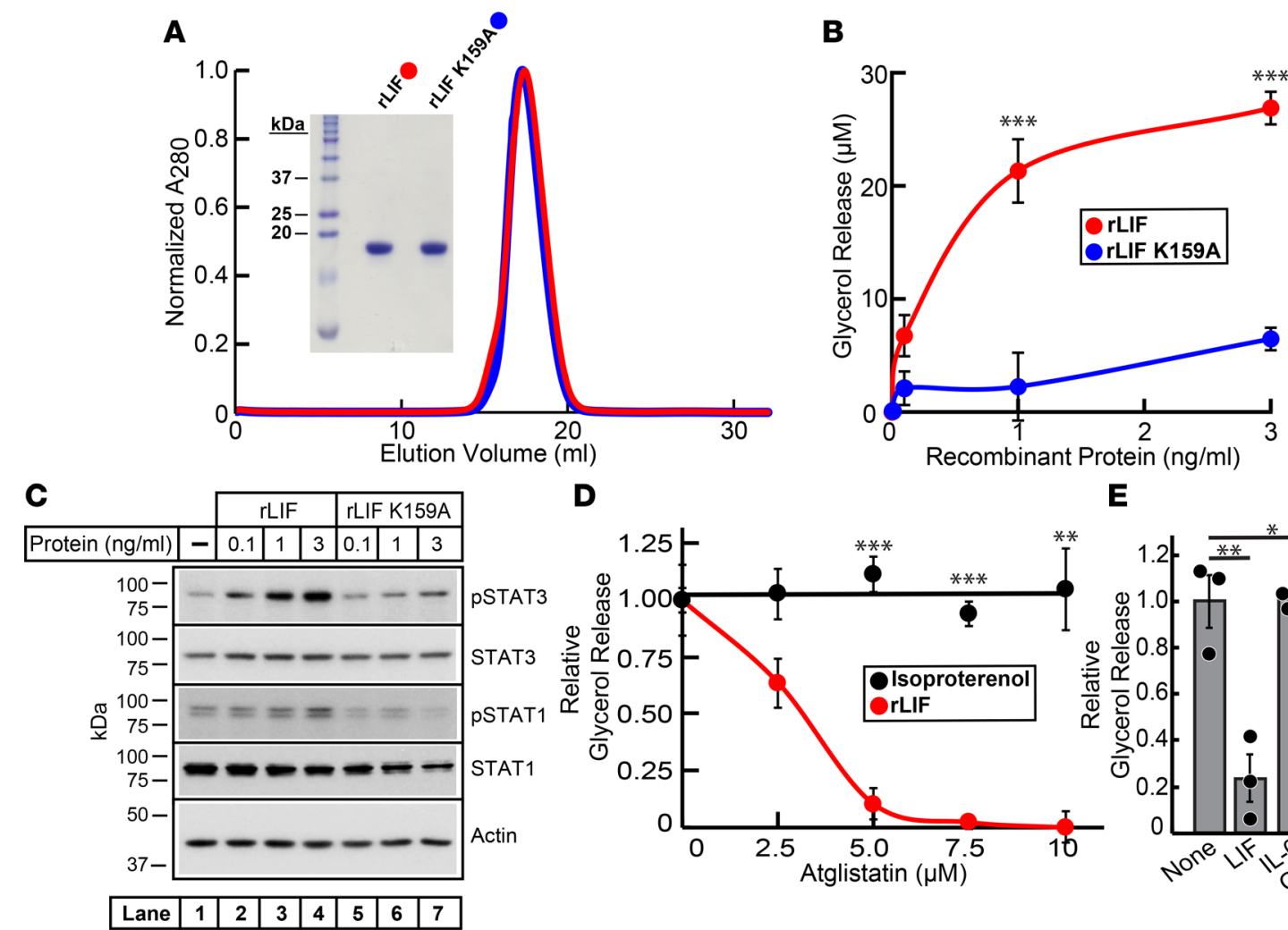

D

E

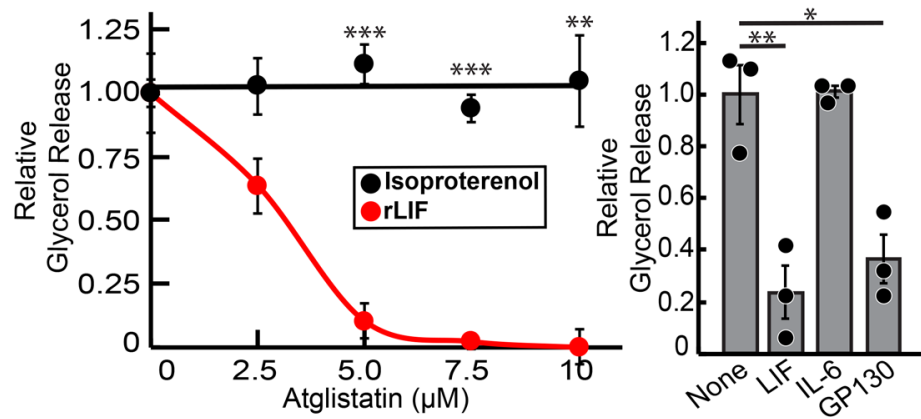

Figure 2. Recombinant LIF induces adipocyte lipolysis through ATGL using its canonical signaling pathway. (A) Gel-filtration chromatography of recombinant proteins. WT recombinant leukemia inhibitory factor (rLIF) and rLIF K159A were purified as described in Methods. Buffer C (1 ml) containing 5-6 mg of rLIF (red) or rLIF K159A (blue) was loaded on to a Tricorn 10/300 Superdex 200 column and chromatographed at a flow rate of $0.5 \mathrm{ml} / \mathrm{min}$. Absorbance at $280 \mathrm{~nm}$ $\left(A_{280}\right)$ was monitored continuously to identify rLIF (red) and rLIF K159A (blue). Maximal A280 values for each protein (rLIF, 576 mAU; rLIF K159A, 728 mAU) were normalized to 1. (Inset) The indicated protein (4 $\mu \mathrm{g}$ of each) was subjected to $15 \%$ SDS/PAGE and stained with Coomassie. (B-D) Differentiated adipocytes in a 12-well format were treated in a final volume of $1.5 \mathrm{ml}$ of medium E supplemented with either the indicated concentration of rLIF or rLIF K159A (B and C) or with $30 \mathrm{nM}$ isoprotererenol or $1 \mathrm{ng} / \mathrm{ml} \mathrm{rLIF}$ in the absence or presence of the indicated concentration of Atglistatin (D). After incubation for 20 hours at $37^{\circ} \mathrm{C}$, medium was collected and glycerol concentration was measured using the adipocyte lipolysis assay (B and $\mathbf{D}$ ), or adipocyte cells were harvested and subjected to IB analysis (C, $10 \mu \mathrm{g} /$ lane) with the indicated antibody as described in Methods. Each data point represents the mean \pm SEM of the absolute glycerol concentration over background (B) or the relative change in medium glycerol concentration compared with conditions containing rLIF without Atglistatin (red, $26 \mu \mathrm{M}$ ) or isoproterenol without Atglistatin (black, $83 \mu \mathrm{M}$ ) (D). (E) SVF adipocytes were differentiated in a 48-well format as described in Methods. Differentiated adipocytes in 48 -well format were treated in a final volume of $300 \mu \mathrm{l}$ of medium E supplemented with $1 \mathrm{ng} / \mathrm{ml} \mathrm{rLIF}$ in the absence or presence of $3 \mu \mathrm{g} / \mathrm{ml}$ of the indicated antibody. After incubation for 20 hours at $37^{\circ} \mathrm{C}$, medium was collected and glycerol concentration was measured using the adipocyte lipolysis assay as described in Methods. Data is shown as dot plots with bars representing mean \pm SEM of the relative change in medium glycerol concentration compared with conditions containing rLIF without antibody $(32 \mu \mathrm{M})$. (A-E) These results were confirmed in $2(\mathbf{E})$ or $3(\mathbf{A}-\mathbf{D})$ independent experiments. ${ }^{*} P<0.05$, ${ }^{* *} P<0.01$, and ${ }^{* * *} P<$ 0.001 based on Student's $t$ test.

of $80 \mu \mathrm{g} / \mathrm{kg}$ i.p. twice daily. Mice were then monitored for changes in body weight and food intake, as well as ECHO MRI changes of fat and lean body mass. As shown in Figure 3A, mice injected with rLIF lost $\sim 15 \%$ of their body weight compared with mice treated with either PBS or rLIF K159A. There was a reduction in food intake in the first 6 days of the experiment in rLIF-administered mice compared with mice injected with PBS or rLIF K159A (Figure 3B, left panel). However, this difference resolved over days 7-21, and there was no overall significant difference in daily food intake over the 21 days of the experiment (Figure 3B, right panel). ECHO MRI results revealed that mice injected with rLIF lost more than $50 \%$ of their adipocyte mass, whereas mice receiving PBS or rLIF K159A injections had no significant change in fat mass (Figure 3C). Lean mass was minimally changed in rLIF-administered mice (Figure 3D). At the conclusion of the experiment, epididymal white adipose tissue (eWAT), gastrocnemius muscle, liver, and spleen were harvested, fixed in formalin, and stained with H\&E (Figure 3E). Histology of the eWAT (left column) showed significant atrophy of adipocytes from mice administered rLIF (middle panel) compared with mice receiving PBS (top panel) or rLIF K159A (bottom panel). There were limited differences in the histology of muscle (second column), liver (third column), or spleen (last column) among cohorts. eWAT was also processed for IB analysis. As shown in Figure 3F, adipose tissue 


\section{- PBS rLIF rLIF K159A}

A
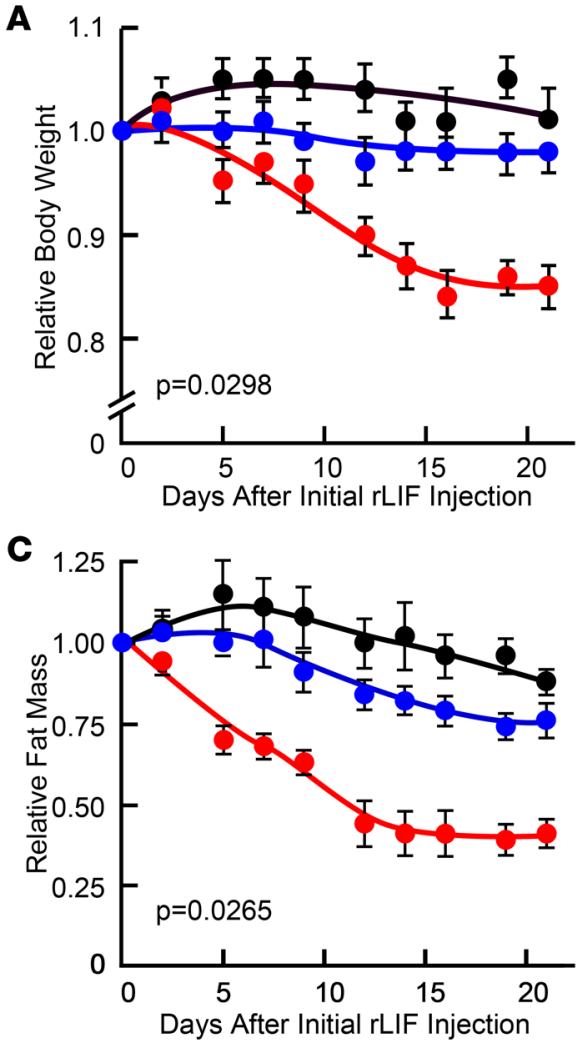

$\mathbf{E}$

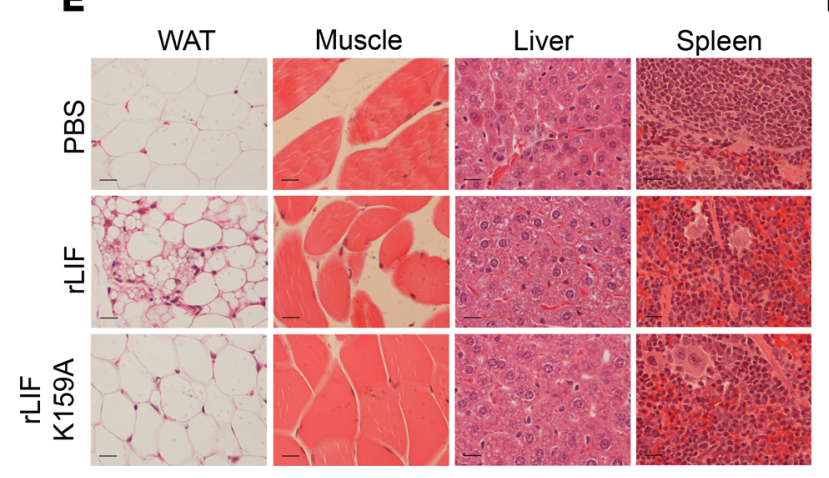

B

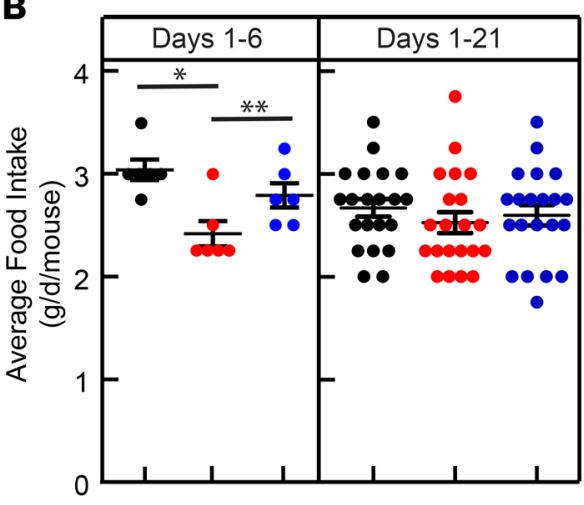

D

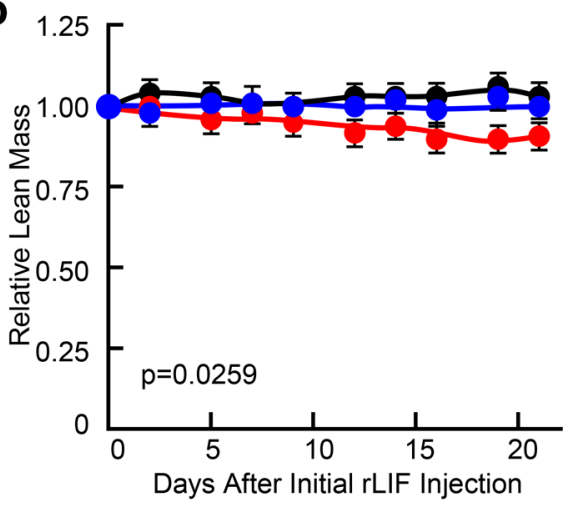

$\mathbf{F}$

Figure 3. LIF induces adipose tissue and body weight loss without persistent change in food intake in Balb/c mice. (A-F) Chow-fed Balb/c mice (10-weekold males) were housed 4 mice per cage and injected i.p. with $100 \mu \mathrm{l} \mathrm{PBS}$ in the absence or presence of rLIF or rLIF K159A at $80 \mu \mathrm{g} / \mathrm{kg}$ body weight twice daily throughout the experiment. Body weight (A), food intake (B), and ECHO MRI measurements of fat mass (C) and lean mass (D) were measured at 9 a.m. at the indicated time points. Body weight, fat mass, and lean mass are shown relative to the average day 0 reference value for each respective cohort. The average values for body weight (A) at day 0 were 21.3, 21.8, and $22.3 \mathrm{~g}$ for the PBS-, rLIF-, and rLIF K159A-treated mice, respectively. The average values for fat mass (C) at day 0 were 2.4, 3.1, and $3.1 \mathrm{~g}$ for the PBS-, rLIF-, and rLIF K159A-treated mice, respectively. The average values for lean mass (D) at day 0 were 16.1, 16.3, and $16.5 \mathrm{~g}$ for the PBS-, rLIF-, and rLIF K159A-treated mice, respectively. Each value represents mean \pm SEM of 4 mice. (E and F) Epididymal white adipose tissue (eWAT), gastrocnemius muscle, liver, and spleen were harvested 21 days after start of injections. Representative sections stained with $\mathrm{H} \& \mathrm{E}(\mathrm{E})$ of each of these tissues are shown. Magnification, 40x; scale bar: $270 \mu \mathrm{m}$. Additionally, eWAT from 2 representative mice from each cohort was processed, and aliquots of cell lysate $(15 \mu \mathrm{g} /$ lane) were subjected to IB analysis (F) with the indicated antibodies as described in Methods. (A-F) These results were confirmed in at least 3 independent experiments. ${ }^{*} P<0.05$ and ${ }^{* *} P<0.01$ based on Student's $t$ test (B) or $P$ value based on use of Generalized Estimating Equation approach comparing multiple groups over time with rLIF-treated mice as the reference value (A, C, and $\mathbf{D})$.

from mice that received rLIF (lanes 3-4) had increased phosphorylated STAT1 (pSTAT1; middle panel) and pSTAT3 (top panel), with no detectable STAT phosphorylation in adipose tissue from mice treated with PBS (lanes 1-2) or rLIF K159A (lanes 5-6). This finding parallels the in vitro rLIF activation of STAT signaling in adipocytes (Figure 2C). 
Decreased leptin signaling overcomes LIF's anorexic effects. rLIF administration to WT mice induced an early transient state of hypophagia that returned to normophagia over 6 days. We hypothesized that there may be an interplay between LIF administration and leptin levels affecting overall net food intake. Mouse models that lack leptin are in the C57BL/6J background; therefore, we first confirmed that rLIF administered to WT C57BL/6J mice also induces adipose loss without persistent hypophagia. WT C57BL/6J mice administered $\mathrm{rLIF}$ lost $\sim 40 \%$ of their adipose mass compared with mice receiving PBS or rLIF K159A (Supplemental Figure 3A). There were no significant changes in lean muscle mass (Supplemental Figure 3B). As shown in Supplemental Figure 3C, rLIF administration reduced food intake during the first 6 days (left panel) compared with mice administered PBS or rLIF K159A. The timing of the acute decrease in food intake was associated with the period of maximal fat loss in the rLIF-treated mice (compare Supplemental Figure 3C, left panel, vs. Supplemental Figure 3A, days 1-6). This transient hypophagia reversed, and food intake returned to baseline levels during days 7-24 (Supplemental Figure 3C, middle panel).

To evaluate the transition of hypophagia to normophagia in rLIF-administered WT mice, we conducted an experiment to determine the change in serum leptin concentrations as a function of adipose loss and food intake. Again, we observed a decrease in fat mass (Figure 4A), with the majority of the fat loss occurring between days 1 and 8 in rLIF-administered mice compared with PBS control. The timing of adipose tissue loss in rLIF-treated mice coincided with an interval of acute hypophagia (Figure 4C, days 2-7). Leptin levels decreased between days 1 and 8 , in association with the loss of adipose tissue (Figure 4B). It is during this time that the acute hypophagia observed with initial rLIF treatment also resolved, with a return to normophagia (Figure 4C, compare days 2-7 vs. days 8-14 and 15-20).

Leptin signals proopiomelanocortin (POMC) neurons of the hypothalamus through the STAT3 pathway to regulate appetite $(30,31)$. LIFR- $\alpha$ is also expressed in POMC neurons of the hypothalamus, and central intracerebroventricular administration of LIF to WT mice increased STAT3 phosphorylation in these neurons, which induced an immediate, limited (4-hour) anorexic effect (32). We measured hypothalamic STAT3 phosphorylation by IB analysis of rLIF-injected WT C57BL/6J mice to evaluate if peripheral administration of rLIF increased STAT3 phosphorylation. As shown in Figure 4D, hypothalamic STAT3 phosphorylation increased over 6 days in rLIF-injected mice (IB, top panel, lanes 6-8) compared with PBS-treated animals (IB, top panel, lanes 1-3). During this time, there was an associated decrease in food intake in rLIF-administered mice (Figure 4D, graph, red, days 1-3 and 4-6). As shown in Figure 4D, as the food intake returned to normal levels (graph, red, days 7-9 and 10-12), there was also a decrease in measured hypothalamic STAT3 phosphorylation (IB, top panel, lanes 9-10) down to pretreatment levels (IB, top panel, compare lanes 6 and 10). Figure 4E details the hypothalamic STAT3 phosphorylation of each individual rLIF-treated mouse of the experiment in Figure 4D. Together, the experiments of Figure 4 suggest that peripheral administration of rLIF increases the phosphorylation of hypothalamic STAT3, which is associated with acute hypophagia. As adipose tissue and leptin levels decrease, there is an associated decrease in hypothalamic STAT3 phosphorylation back to pretreatment levels that corresponds with a return to normophagia.

To validate that decreased leptin levels in rLIF-treated WT mice were responsible for a return of food intake from hypophagia to normophagia, we coadministered rleptin to our rLIF-injected mouse model. Mice received rLIF for 15 days, resulting in a loss of adipose mass of $\sim 30 \%-40 \%$ and a body weight loss of $\sim 10 \%$. Mice were then randomized into 4 groups receiving injections containing PBS, rLIF, rleptin, or a combination of rLIF and rleptin. As shown in Figure 5A, mice receiving the combination of rLIF and rleptin had continued hypophagia compared with mice injected with PBS and rLIF. The coadministered rLIF and rleptin mice also had a further decrease in fat mass (Figure 5B) and body weight (Figure 5C) compared with mice injected with PBS, rLIF, and rleptin. These results suggest that giving leptin back to rLIF-chronically treated mice reversed the counterbalance of reduced leptin levels, allowing rLIF's central effect of hypophagia to persist and resulting in further body weight and adipose loss.

LIF induces loss of adipose tissue in ob/ob mice. Next, we determined if rLIF induced weight loss in mouse models of obesity that lack leptin signaling. Eleven-week-old male $o b / o b$ mice were injected with either PBS, rLIF, or rLIF K159A ( $80 \mu \mathrm{g} / \mathrm{kg}$ i.p.) twice daily for 48 days (treatment phase), followed by another 29 days without injections (posttreatment phase). Mice were monitored for changes in body weight, food intake, and ECHO MRI changes of fat and lean mass levels throughout the experiment (Figure 6). As shown in Figure $6 \mathrm{~A}$, mice injected with $\mathrm{rLIF}$ during the treatment phase (left panel) had a $>30 \%$ decrease in body weight compared with mice treated with either PBS or rLIF K159A. Once injections were discontinued (right panel), 


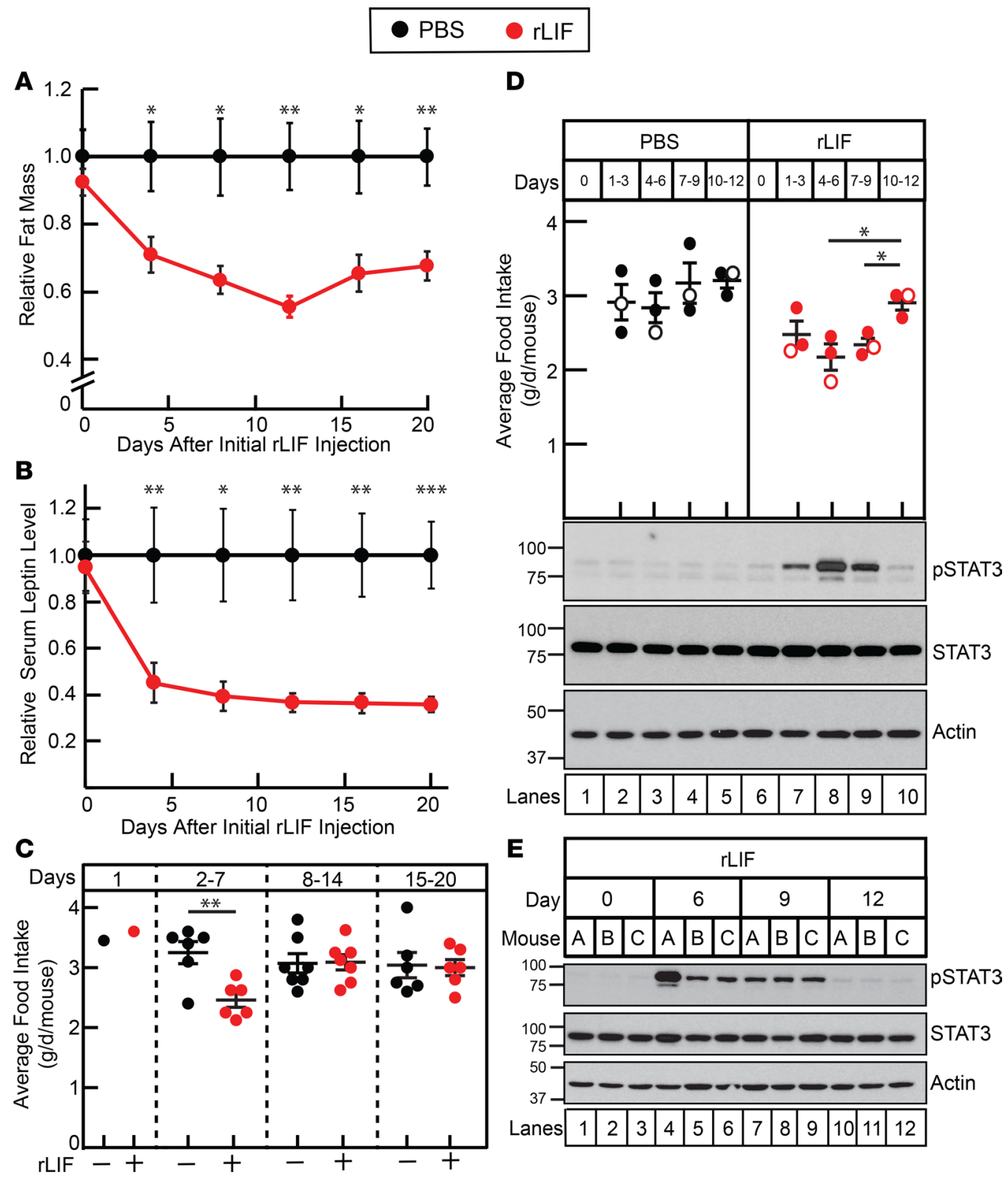

Figure 4. LIF's central anorexic effect is reversed by decreased leptin signaling. (A-C) Leptin levels relative to fat mass and food intake in rLIF-treated C57BL/6) mice. Chow-fed C57BL/6] mice (8-week-old males) were housed 4 mice per cage and injected i.p. with $100 \mu$ l PBS in the absence or presence of rLIF at $80 \mu \mathrm{g} / \mathrm{kg}$ body weight twice daily throughout the experiment. ECHO MRI measurements of fat mass (A), food intake (C), and serum leptin (B) were measured as described in Methods and are shown relative to the PBS-treated control mice at the indicated time points. The average values for fat mass (A) of PBS-treated control mice were 2.8, 2.7, 2.8, 3.0, 3.0, and $3.2 \mathrm{~g}$ for days $0,4,8,12,16$, and 20, respectively. The average values for leptin concentration (B) of PBS-treated control mice were 3.0, 2.0, 2.9, 2.7, 3.2, and $3.3 \mathrm{ng} / \mathrm{ml}$ for days $0,4,8,12,16$, and 20, respectively. Each value represents mean \pm SEM of 8 mice. ( $\mathbf{D}$ and $\mathbf{E}$ ) Chow-fed C57BL/6) mice (11-week-old males) were housed 3 mice per cage and injected with PBS in the absence or presence of rLIF at $80 \mu \mathrm{g} / \mathrm{kg}$ body weight i.p. twice daily for the indicated time frame, and food intake was measured. Every 3 days, 3 mice from each cohort were sacrificed, followed by harvesting and processing of the hypothalamus as described in the Methods. Aliquots ( $30 \mu \mathrm{g} / \mathrm{lane}$ ) of pooled hypothalamic cell lysate (D) or individual mouse hypothalamic cell lysate (E) from 3 mice treated identically were subjected to IB analysis with the indicated antibodies as described in Methods. The unfilled circles represent the average food intake from the day the 3 mice from each cohort were sacrificed for hypothalamic processing. (A-E) These results were confirmed in 3 independent experiments. ${ }^{*} P<0.05$, ${ }^{* *} P<0.01$, and ${ }^{* * *} P<0.001$ based on Student's $t$ test comparing rLIF-treated mice with PBS-treated mice at the indicated time (A-D).

the rLIF-injected cohort rapidly gained body weight, approaching the body weights measured in mice treated with PBS or rLIF K159A. The decrease in body weight found during the treatment phase in $o b / o b$ mice receiving rLIF correlated with the decrease in adipose tissue mass quantified by ECHO MRI (Figure 6B, left panel). These mice also demonstrated a steep increase in their fat mass during the posttreatment phase, matching that found in the control cohorts (Figure 6B, right panel). No differences were observed in lean 
A

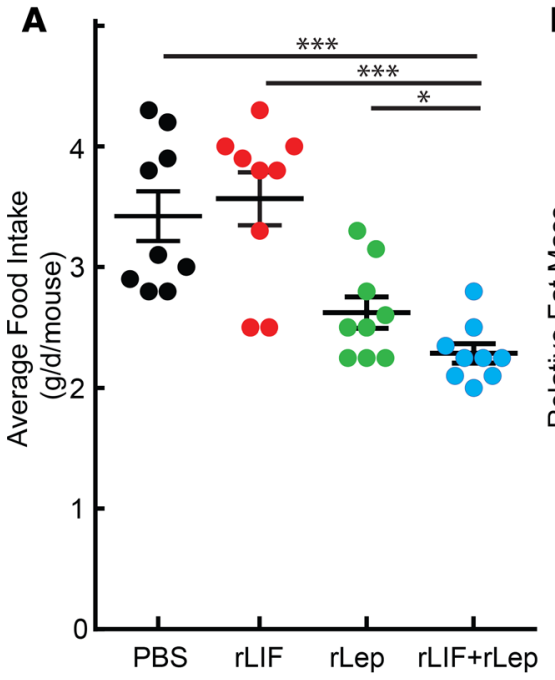

B

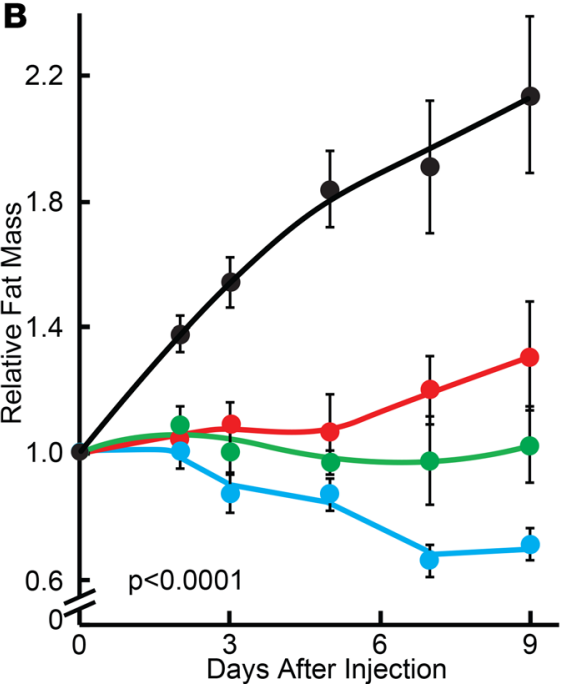

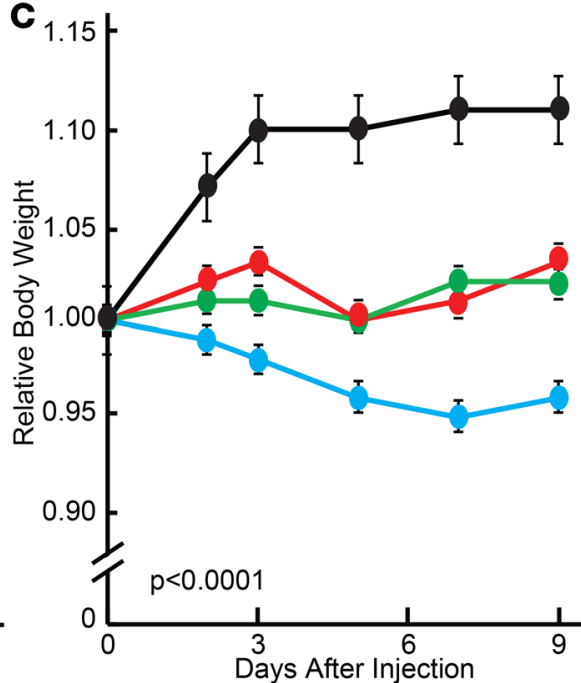

Figure 5. LIF's central effect persists with coadministration of leptin. (A-C) Combination treatment of [57BL/6] mice with rLIF and leptin. On day -15 , chow-fed C57BL/6) mice (11-week-old males) were injected i.p. with $100 \mu \mathrm{l}$ PBS containing $80 \mu \mathrm{g} / \mathrm{kg}$ body weight rLIF twice daily for 15 days with average fat mass loss of $\sim 30 \%-40 \%$ and weight loss of $\sim 10 \%$. On day 0 , mice were randomized and housed 4 mice per cage and treated with $100 \mu$ l PBS in the absence or presence of $80 \mu \mathrm{g} / \mathrm{kg}$ body weight rLIF twice daily and/or $5 \mathrm{mg} / \mathrm{kg}$ leptin once daily for 9 days. ECHO MRI measurements of fat mass (B), body weight (C), and food intake (A) were measured at the indicated time points and are shown relative to the average day 0 reference value for each respective cohort. The average day 0 values for fat mass were 1.7, 1.7, 1.6, and $1.7 \mathrm{~g}$ and body weight were 22.1, 23.5, 21.5, and $23.1 \mathrm{~g}$ for the PBS, rLIF, rleptin, and rLIF plus rleptin cohorts, respectively. Each value represents dot plot with mean \pm SEM (A) or mean \pm SEM (B-C) of 4 mice. (A-C) These results were confirmed in 2 independent experiments. ${ }^{*} P<0.05$ and ${ }^{* *} P<0.001$ based on Student's $t$ test (C) or $P$ value based on use of Generalized Estimating Equation approach comparing multiple groups over time with rLIF + rleptin-treated mice as the reference value (A and $\mathbf{B})$.

tissue mass during the treatment and posttreatment phases (Figure 6C). Food intake of $o b / o b$ mice treated with rLIF was reduced by $\sim 50 \%$ compared with mice injected with either PBS or rLIF K159A (Figure 6D, left panel). As shown in Figure $6 \mathrm{E}$, the change in food intake remained persistent during the entire treatment phase, resulting in a significant difference in food intake in mice receiving rLIF. This is in contrast to the findings shown in Figures 3B and Figure 4C, in which rLIF administration to WT mice with an intact leptin system did not persistently alter food intake.

We next measured hypothalamic STAT3 phosphorylation by IB analysis of rLIF-injected $o b / o b$ mice to evaluate if peripheral administration of rLIF increased STAT3 phosphorylation. As shown in Figure 6F, hypothalamic STAT3 phosphorylation increased and persisted throughout the 15 days of the experiment (IB, top panel, lanes 7-12) compared with PBS-treated animals (IB, top panel, lanes 1-6). There was also a persistent decrease in food intake in rLIF-administered mice (Figure 6F, graph, red) compared with PBS-treated animals (Figure 6F, graph, black). This data suggest that rLIF-induced hypothalamic STAT3 phosphorylation and hypophagia cannot return toward normal levels in mice that lack the leptin signaling axis. This is in contrast to the finding shown in Figure 4D, in which rLIF administration to WT mice with an intact leptin system did not maintain a persistent increase in their STAT3 phosphorylation or a persistent decrease in food intake.

LIF has central and noncentral roles in leptin signaling-deficient mice. As shown above, rLIF administration persistently decreased food intake in $o b / o b$ mice, which was not observed in WT mice. However, both mouse models displayed a significant loss of adipose tissue and body weight relative to controls, suggesting that, in WT mice, there is an appetite-independent contribution to rLIF's ability to induce adipose loss. To determine if the reduction in food intake in the $o b / o b$ mice was solely responsible for the weight loss, we performed a pair-feeding experiment in which PBS- and rLIF K159A-treated $o b / o b$ animals were restricted to the same daily food intake as rLIF-treated $o b / o b$ animals. As shown in Figure 7A, all the pair-fed PBS- and rLIF K159A-treated mice had the same food intake over 18 days of the experiment as the rLIF-treated mice fed ad libitum. Despite the same food intake, ob/ob mice treated with rLIF lost more weight than those mice fed ad libitum or pair-fed receiving PBS or rLIF K159A (Figure 7B). The body weight difference corresponded to a $15 \%-20 \%$ decrease in fat mass (Figure $7 \mathrm{C}$ ). 
A

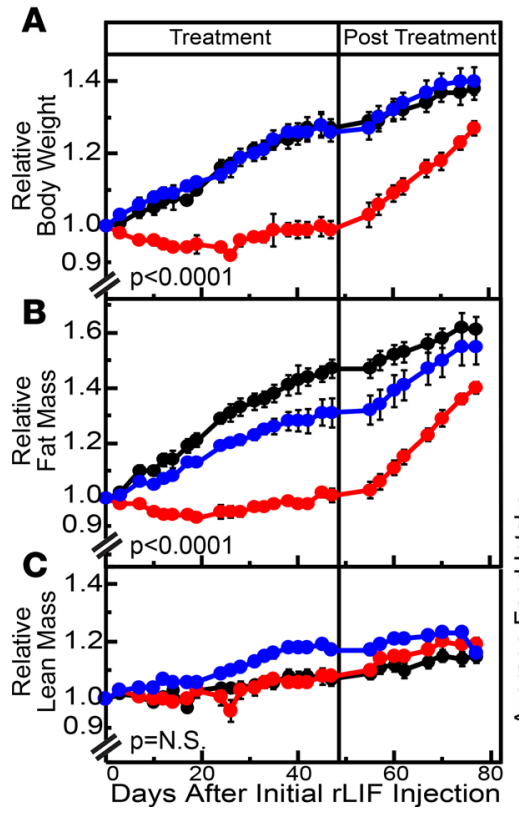

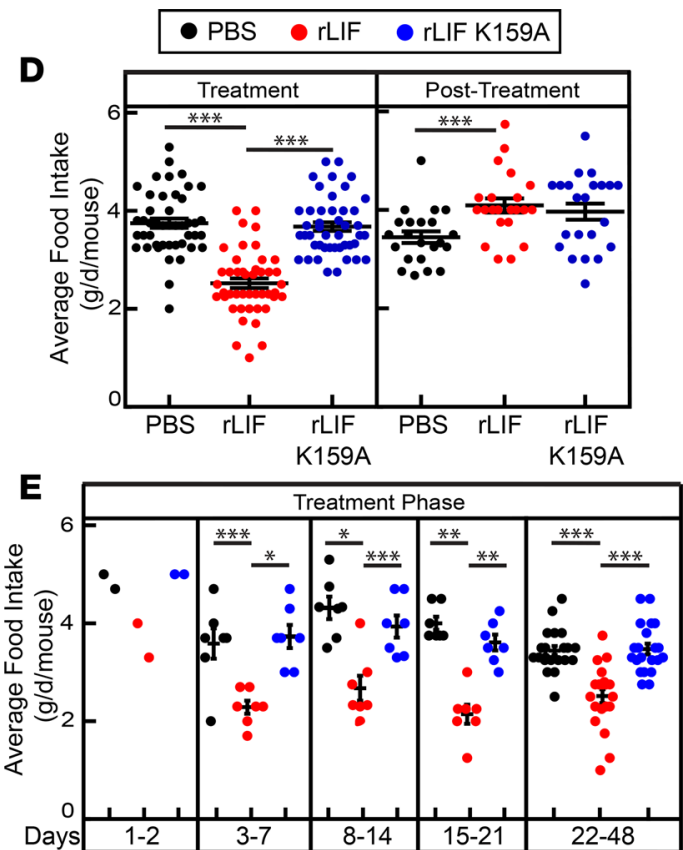

$\mathbf{F}$

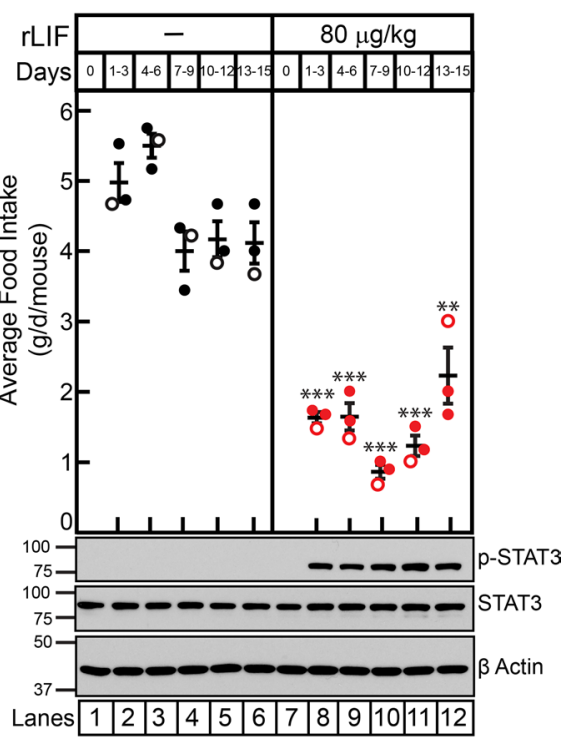

Figure 6. LIF induces a persistent decrease in body weight, adipose mass, and food intake in ob/ob mice. (A-E) Chow-fed Lep $p^{\circ b} / J, o b / o b$, mice (11-weekold males) were housed 4 mice per cage and injected i.p. with $100 \mu \mathrm{l} \mathrm{PBS}$ in the absence or presence of rLIF or rLIF K159A at $80 \mu \mathrm{g} / \mathrm{kg}$ body weight twice daily for 48 days (treatment) and subsequently followed for another 29 days (posttreatment) without injections. Body weight (A), food intake (D and E), and ECHO MRI measurements of fat mass (B) and lean mass (C) were measured at the indicated time points for 77 days. Body weight, fat mass, and lean mass are shown relative to the average day 0 reference value for each respective cohort. The average values for body weight (A) at day 0 were $39.5,39.5$, and $39.3 \mathrm{~g}$ for the PBS-, rLIF-, and rLIF K159A-treated mice, respectively. The average values for fat mass (B) at day 0 were 20.1, 20.6, and 20.9 g for the PBS-, rLIF-, and rLIF K159A-treated mice, respectively. The average values for lean mass (C) at day 0 were $16.7,15.8$, and $16.5 \mathrm{~g}$ for the PBS-, rLIF-, and rLIF K159A-treated mice, respectively. (F) Chow-fed Lepob/J, ob/ob, mice (10-week-old males) were housed 3 mice per cage and treated with PBS or rLIF as above for the indicated time interval, and food intake was measured. Every 3 days, 3 mice from each cohort were sacrificed, followed by harvesting and processing of the hypothalamus as described in the Methods. Aliquots ( $30 \mu \mathrm{g} / \mathrm{lane}$ ) of pooled hypothalamic cell lysate from 3 mice treated identically were subjected to IB analysis with the indicated antibodies as described in Methods. The unfilled circles represent the average food intake from the day the 3 mice from each cohort were sacrificed for hypothalamic processing. (A-F) Each value represents mean \pm SEM $(\mathbf{A}-\mathbf{C})$ or dot plots with mean \pm SEM (D-F) of 3 mice $(\mathbf{F})$ or 4 mice $(\mathbf{A}-\mathbf{E})$. These results were confirmed in $2(\mathbf{F})$ or 3 independent experiments $(\mathbf{A}-\mathbf{E}) .{ }^{*} P<0.05,{ }^{*} P<0.01$, and ${ }^{* * *} P<0.001$ based on Student's $t$ test comparing rLIF-treated mice with PBS- or rLIF K159A-treated mice over the respective time interval (D-F) or $P$ value based on use of Generalized Estimating Equation approach with rLIF-treated mice as the reference value (A-C).

LIF promotes decreased food intake and adipose tissue loss in leptin deficiency $(o b / o b)$. Interestingly, leptin has a long-chain helical structure similar to LIF (33), and both induce STAT3 activation. Therefore, we next determined if LIF works directly through the leptin receptor to facilitate weight loss using mice that lack the leptin receptor ( $d b / d b)(34)$. These $d b / d b$ mice were injected with either PBS, rLIF ( $80 \mu \mathrm{g} / \mathrm{kg}$ i.p.) or rLIF K159A ( $80 \mu \mathrm{g} / \mathrm{kg}$ i.p.) twice daily for 47 days (treatment phase), followed by 31 days without injections (posttreatment phase). Mice were monitored for changes in body weight, food intake, and ECHO MRI changes of fat and lean mass throughout the experiment. As shown in Figure 8A, mice injected with rLIF during the treatment phase (left panel) lost $\sim 30 \%$ body weight relative to those mice treated with either PBS or rLIF K159A. Once injections were discontinued (right panel), the rLIF-injected cohort rapidly gained body weight, approaching the body weight observed in mice treated with PBS or rLIF K159A. These results are similar to those of rLIF-injected $o b / o b$ mice (Figure 6A).

The decrease in body weight measured in $d b / d b$ mice receiving rLIF during the treatment phase was a result of a decrease in adipose tissue, as quantified by ECHO MRI (Figure 8C, left panel). Similar to results reported in $o b / o b$ mice, $d b / d b$ mice had a rapid increase in their fat mass during the posttreatment phase (Figure 8C, right panel). Limited differences were observed in lean tissue mass among these cohorts during the treatment and posttreatment phases (Figure 8D). As shown in Figure 8B (left panel), $d b / d b$ mice treated with $\mathrm{rLIF}$ also showed a persistent decrease in food intake compared with mice injected with either PBS or rLIF K159A during the treatment phase. This finding is similar to rLIF-treated $o b / o b$ mice and again is in contrast to the results obtained in WT mice, in which rLIF administration only transiently decreased 
A

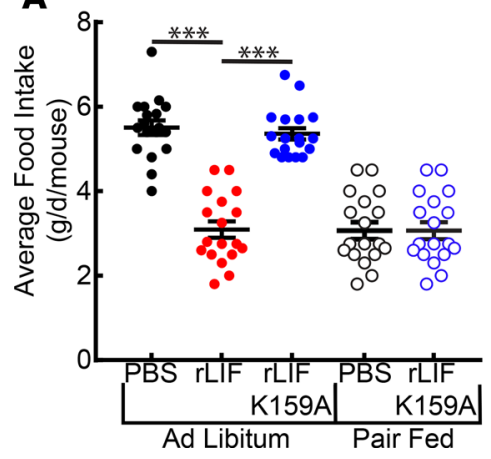

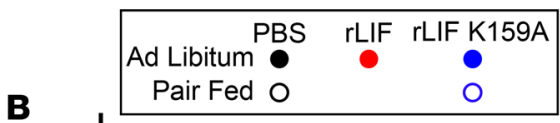

B

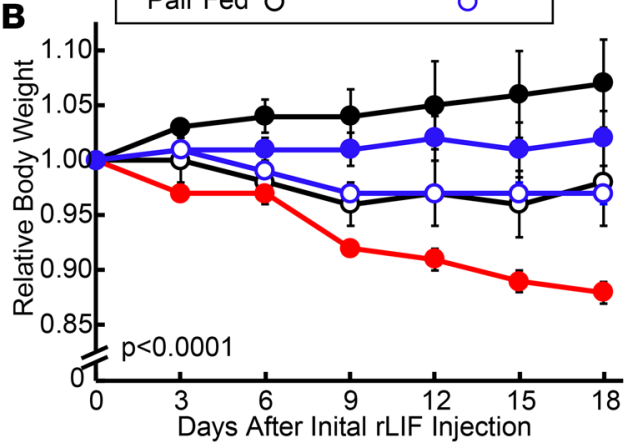

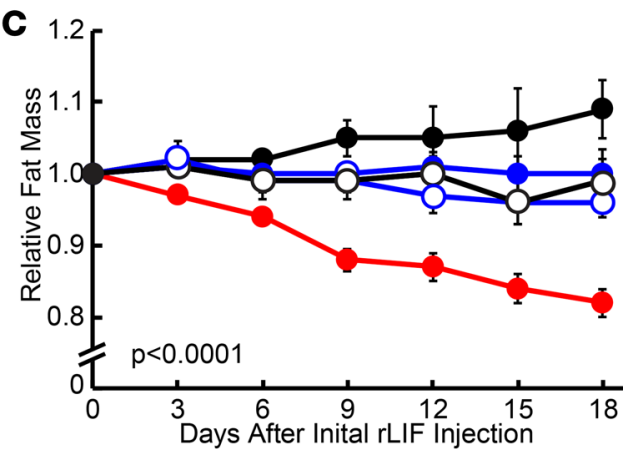

Figure 7. LIF induces central and noncentral effects in ob/ob mice. (A-F) Chow-fed Lep ${ }^{\circ b} / J, o b / o b$, mice (11-week-old males) were housed individually and injected i.p. with $100 \mu \mathrm{I}$ PBS in the absence or presence of rLIF or rLIF K159A at $80 \mu \mathrm{g} / \mathrm{kg}$ body weight twice daily for 18 days throughout the experiment. PBS- and rLIF K159A-treated mice were either fed ad libitum or pair fed to the food intake of rLIF-treated mice fed ad libitum. Food intake (A), body weight (B), and ECHO MRI measurement of fat mass (C) were measured at the indicated time points. Body weight and fat mass are shown relative to the average day 0 reference value for each respective cohort. The average values for body weight (B) at day 0 were $44.5,47.0$, and 46.3 g for the PBS-, rLIF-, and rLIF K159A-treated mice fed ad libitum, respectively. The average day 0 values of body weight for the PBS- and rLIF K159A-treated mice pair fed were 45.9 and $46.0 \mathrm{~g}$, respectively. The average values for fat mass (C) at day 0 were $25.4,24.0$, and $24.0 \mathrm{~g}$ for the PBS-, rLIF-, and rLIF K159A-treated mice fed ad libitum, respectively. The average day 0 values of fat mass (C) for the PBS- and rLIF K159A-treated mice pair fed were 24.5 and $25.6 \mathrm{~g}$, respectively. Each value represents mean \pm SEM of 4 mice. These results were confirmed in 2 independent experiments. ${ }^{* *} P<0.001$ based on Student's $t$ test or $P$ value based on use of Generalized Estimating Equation approach comparing multiple groups over time with rLIF-treated mice as the reference value (A-C).

food intake (Figure 3B and Figure 4C). Combined, our results suggest that rLIF's effects on adipose loss and food intake does not require signaling through the leptin receptor. These results also are consistent with leptin's role to return food intake back to pretreatment levels in $\mathrm{rLIF}$-administered mice.

\section{Discussion}

Here, using an unbiased biochemical screen of secreted factors from a cell line that induces CX in vivo, we identified LIF as a protein that induced lipolysis in adipocytes. LIF is most highly expressed by cancers that promote CX in humans - lung, renal cell, and gastrointestinal (Supplemental Figure 2). Increased circulating levels of LIF were associated with multiple cancer CX mouse models displaying adipose loss. LIF was secreted from C26c20 cancer cells and induced lipolysis in adipocytes. LIF-induced lipolysis signaled through the coreceptor gp130 and resulted in STAT1 and STAT3 phosphorylation, as reported in other tissues. Unlike isoproterenol-induced lipolysis, which relies on HSL function, LIF-mediated lipolysis was dependent on ATGL activity (Figure 2D). This finding is consistent with data from Das and colleagues (8), who showed adipose deletion of ATGL-protected mice from cancer-induced CX. WT mice administered rLIF demonstrated adipose and body weight loss, consistent with a CX phenotype.

Although our in vitro assay confirmed that LIF induced lipolysis, we identified additional functions for LIF in vivo. I.p. administration of rLIF to mice led to adipose tissue and body weight loss through both peripheral and central effects. LIF's central effect in WT mice manifested as transient hypophagia, possibly mediated through direct phosphorylation of STAT3 in the hypothalamus. LIF and leptin both can activate STAT pathways and signal through POMC neurons in the appetite center of the hypothalamus (30-32). Interestingly, LIF-induced body weight and adipose loss was associated with a transient reduction in food intake that paralleled a decrease in leptin. The reduction in leptin was associated with a decrease in STAT phosphorylation back to baseline levels and a stimulation in appetite-restoring food intake to pretreatment levels. This return of hypothalamic STAT phosphorylation and food intake back to baseline was not observed in the leptin-deficient $o b / o b$ rLIF-treated mice (Figure $6 \mathrm{~F}$ ). To confirm leptin was responsible for the change in food intake limiting rLIF-induced weight loss, we (a) coadministered rleptin and rLIF to the WT mouse model and (b) administered rLIF to leptin-deficient $o b / o b$ mice. Coadministering rleptin to rLIF-chronically treated WT mice allowed rLIF's central effect of hypophagia to persist, resulting in further body weight and adipose loss (Figure 5). Unlike WT mice, rLIF-administered $o b / o b$ mice demonstrated a persistent decrease in food intake, which was also associated with a persistent decrease in body 


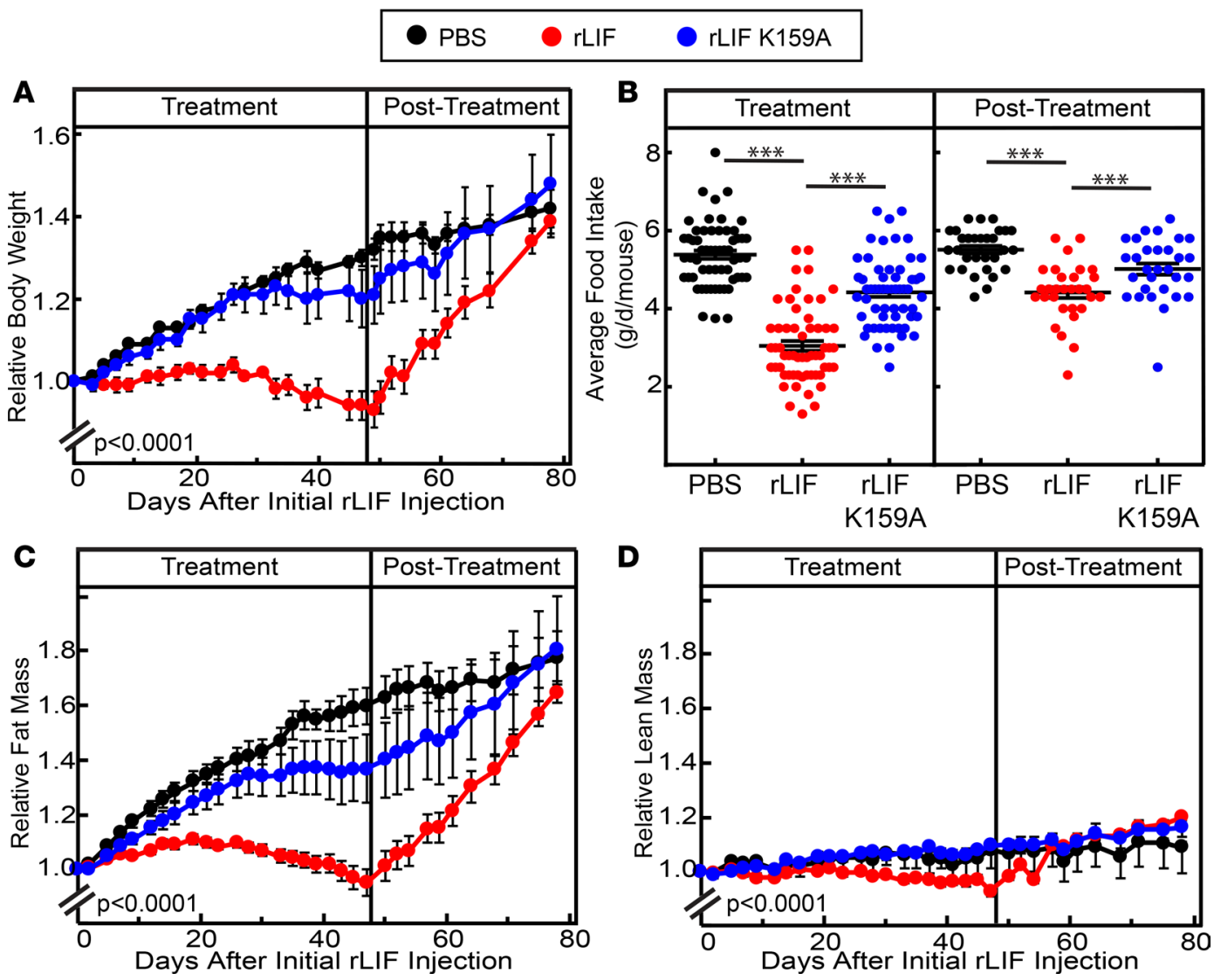

Figure 8. LIF induces a persistent decrease in body weight, adipose mass, and food intake in $\mathbf{d b} / \mathbf{d b}$ mice. (A-D) Chow-fed Leprdb/J, $d b / d b$, mice (8-weekold males) were housed 4 mice per cage and injected i.p. with $100 \mu \mathrm{lPBS}$ in the absence or presence of rLIF or rLIF K159A at $80 \mu \mathrm{g} / \mathrm{kg}$ body weight twice daily for 47 days (treatment) and subsequently followed for another 31 days (posttreatment) without injections. Body weight (A), food intake (B), and ECHO MRI measurements of fat mass (C) and lean mass (D) were measured at 9 a.m. at the indicated time points for 78 days. Body weight, fat mass, and lean mass are shown relative to the average day 0 reference value for each respective cohort. The average values for body weight (A) at day 0 were 35.8 , 34.8, and $34.3 \mathrm{~g}$ for the PBS-, rLIF-, and rLIF K159A-treated mice, respectively. The average values for fat mass (C) at day 0 were $16.8,16.7$, and $16.9 \mathrm{~g}$ for the PBS-, rLIF-, and rLIF K159A-treated mice, respectively. The average values for lean mass (D) at day 0 were 16.1, 15.3, and 15.1 g for the PBS-, rLIF-, and rLIF K159A-treated mice, respectively. Each value represents mean \pm SEM of 4 mice. These results were confirmed in 2 independent experiments. ${ }^{* * *} P$ $<0.001$ based on Student's $t$ test (B) or $P$ value based on use of Ceneralized Estimating Equation approach comparing multiple groups over time with rLIF-treated mice as the reference value (A, C, D).

weight and adipose mass. Leptin and LIF have similar long-chain helical structures (33) and both induce STAT activation. To determine if LIF signals through the leptin receptor, we administered rLIF to leptin receptor-deficient $d b / d b$ mice. Similar to $o b / o b$ mice, $d b / d b$ mice also demonstrated a persistent decrease in food intake with an associated decrease in body weight and adipose mass, suggesting that LIF's signaling of the hypothalamus is independent of the leptin receptor. To determine if LIF-induced weight loss was solely due to decreased food intake, we performed pair-feeding studies in rLIF-treated $o b / o b$ mice (Figure 7). We found that rLIF administration decreased body weight and fat mass more than controls, suggesting that half of rLIF's contributions to adipose loss is secondary to its central effect of hypophagia (Figure 7B, black circles, closed vs. open) and the other half is due to a peripheral effect (Figure 7B, black open circles vs. red closed circles). Currently, we are generating adipocyte-specific LIFR- $\alpha$-null mice and POMC neuron-specific $L I F R$ - $\alpha$-null mice to quantify the relevant central versus peripheral contributions of rLIF on body weight and adipose loss.

A working model that proposes how LIF induces adipose tissue loss in mice with an intact leptin axis is shown in Figure 9. LIF has 2 major actions: it peripherally stimulates lipolysis in adipose tissue, and it centrally triggers early hypophagia by acting on the hypothalamus, likely through LIF receptor activation of STAT3 pathways. Both events occur during the early exposure to a CX factor(s), causing adipose tissue loss, which in turn leads to reduced leptin secretion over time. The chronic decrease in leptin results in a 


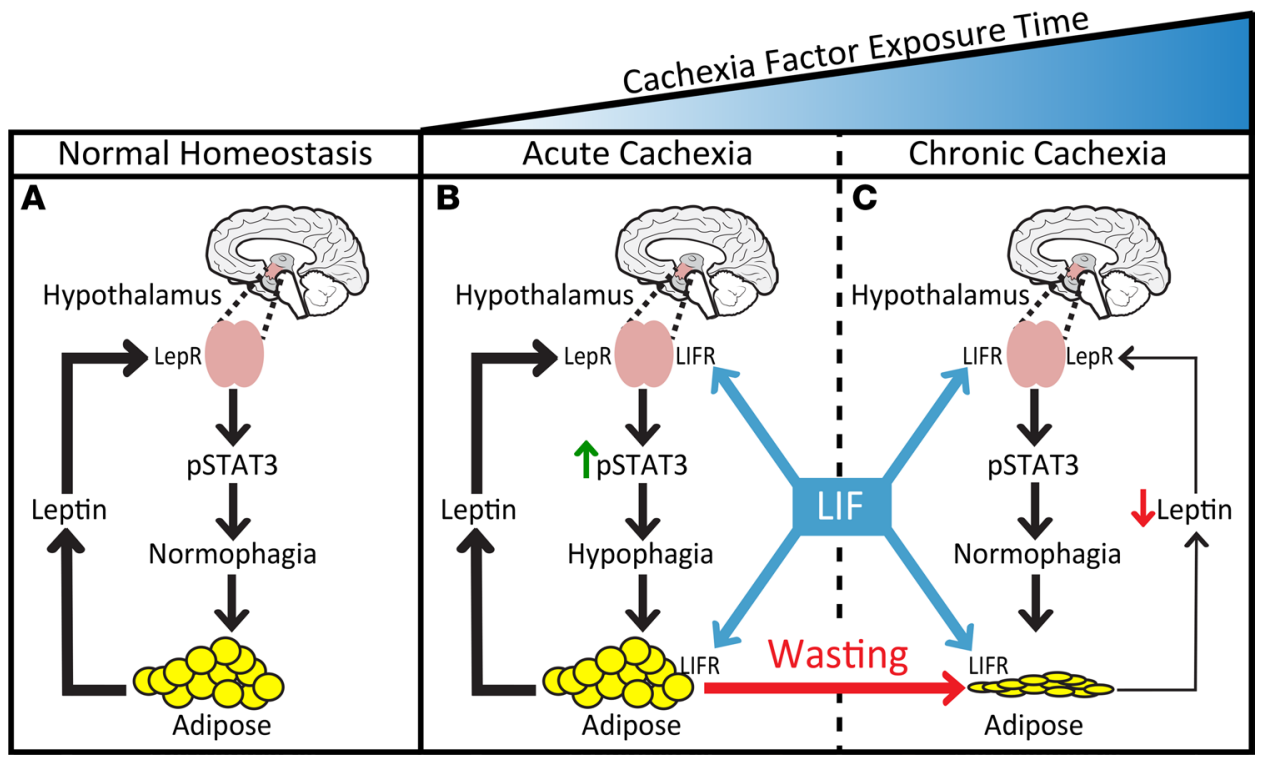

Figure 9. Working model of LIF-induced adipose tissue loss and leptin's response in cachexia. (A) In normal homeostasis, leptin levels that are proportional to adipose mass are reached to maintain baseline hypothalamic PSTAT3, resulting in normophagia. (B) Cachexia factors work peripherally on adipose tissue and centrally with leptin on the hypothalamus to increase pSTAT3, resulting in hypophagia. (C) As body weight and adipose mass decrease in the setting of cachexia factors, there is a corresponding suppression of leptin secretion into serum, decreasing the extent of its hypothalamic signaling. Overall, the increase in cachexia factor signaling and the decrease in leptin signaling of the hypothalamus have a net effect of returning pSTAT3 back to baseline levels, normalizing food intake.

return of food intake approaching normophagia, owing to a decrease in hypothalamic STAT3 phosphorylation through the leptin receptor pathway. The increase in LIF receptor activation and the decrease in leptin receptor signaling consequently have a net effect of normalizing food intake in the setting of overall adipose tissue loss and decreased body weight. It is likely that LIF's noncentral effect on adipocyte lipolysis permits sustained differences in body weight despite normal food intake. This is consistent with data in Figure 5, demonstrating that mice chronically treated with rLIF maintained their reduction in body weight and adipose mass, whereas those animals that stopped chronic rLIF treatment (PBS) regained their body weight and adipose mass in the setting of equivalent food intake.

The current studies provide insight into the clinical paradox of human CX patients who describe losing weight despite eating normally. We have found that the extent of LIF's peripheral and central effects on body weight and adipose tissue loss is limited by leptin's counterregulation in WT animals with an intact leptin axis. In the clinical setting, patients with cancer CX continue to lose weight in the setting of perceived normophagia. One difference between our animal studies and clinical cancer CX patients is that mice were administered a constant amount of LIF throughout the entire experiment. Eventually, a steady state is reached that is determined by the balance of CX factor and leptin response. Patients have an ever-expanding cancer burden and immune response with increasing circulating levels of multiple CX factors over time, likely resulting in constant adjustment of leptin levels in an attempt to maintain normophagia. It is conceivable that - at the extreme end of the CX spectrum, in which leptin counterregulation has been exhausted - the phenotype can manifest as frank anorexia.

In an attempt to block the murine model of cancer $C X$, we are creating a monoclonal antibody against LIF, with an expectation that the antibody may have neutralizing benefits in cachectic settings. It is probable, however, that the LIF antibody will only partially suppress cancer CX wasting, since multiple factors - including other IL- 6 family members - are expressed by tumors/immune cells and offer similar wasting effects as $\operatorname{LIF}(20,35,36)$. The ability of chronic disease/immune conditions to stimulate a milieu of factors that affect whole body metabolism, food intake, and energy consumption may explain why single agents that target CX have likely failed to block this syndrome. The IL-6 family of ligands relies on their respective receptors and their common coreceptor, gp130, for signaling. Targeting this coreceptor or its downstream pathway could abrogate the central and peripheral effects of this class of cytokines on CX. 
Combined, our studies show that LIF is a tumor-secreted molecule that promotes adipose tissue loss through 2 mechanisms: (a) a peripheral effect that includes adipocyte lipolysis and (b) a central effect that induces anorexia. The effect of LIF and IL- 6 family members on sustained adipose wasting is counterbalanced by changes in leptin levels and signaling, limiting the extent of the central actions induced by these CX factors. A more detailed understanding of how LIF mediates lipolysis and anorexia may lead to new therapeutic opportunities to treat not only CX, but also obesity-related comorbidities.

\section{Methods}

Additional information for liquid chromatography/tandem mass spectrometry analysis, and IB analysis can be found in the Supplemental Methods.

Materials. We obtained Coomassie Brilliant Blue R-450 and Precision Plus Protein Kaleidoscope Standards from Bio-Rad; protease inhibitor cocktail set III from Calbiochem; 3-isobutyl-1-methylxanthine (IBMX), Atglistatin, BSA, dexamethasone, endotoxin-free PBS, FBS, free glycerol reagent, glycerol, rIL-6, phenylmethanesulfonyl fluoride (PMSF), Ponceau S, rleptin, and tris (2-carboxyethyl) phosphine (TCEP) from MilliporeSigma. Isoproterenol was obtained from Cayman Chemical. Mouse leptin ELISA kit was obtained from Crystal Chem. We obtained monoclonal anti- $\beta$-actin (catalog 3700 ), polyclonal antiSTAT1 (catalog 9172), monoclonal anti-pSTAT1 (catalog 7649), monoclonal anti-STAT3 (catalog 9139), and monoclonal anti-pSTAT3 (catalog 9138) from Cell Signaling Technology; polyclonal anti-LIF (catalog AB-449-NA), polyclonal anti-gp130 (catalog AF468), and polyclonal anti-angiopoietin-like protein 2 (catalog AF1444) from R\&D Systems; monoclonal anti-IL-6 (catalog MM600C) and rTNF $\alpha$ (catalog PMC3014) from Invitrogen; and monoclonal anti-TNF $\alpha$ (catalog MM350C) from Thermo Fisher Scientific. Purified rTEV protease was a gift from Arun Radhakrishnan (UT Southwestern Medical Center).

Buffers and culture medium. Buffer A contained $10 \mathrm{mM}$ sodium phosphate ( $\mathrm{pH}$ 7.5). Buffer B contained $20 \mathrm{mM}$ Tris (pH 7.5). Buffer C contained $50 \mathrm{mM}$ Tris ( $\mathrm{pH} 7.5)$ and $150 \mathrm{mM} \mathrm{NaCl}$. Buffer D was buffer $\mathrm{C}$ with the addition of $1 \mathrm{mM}$ DTT. Buffer E contained $10 \mathrm{mM}$ Tris-HCL (pH 6.8), $100 \mathrm{mM} \mathrm{NaCl}, 1 \%$ (w/v) SDS, 1 mM EDTA, 1 mM EGTA, phosphatase inhibitor cocktail Set I and Set II (MilliporeSigma, 1:1,000), and protease inhibitor cocktail $(1: 1,000)$. Medium A was DMEM high glucose (D6429; MilliporeSigma). Medium B was medium A supplemented with 100 units $/ \mathrm{ml}$ penicillin, $100 \mu \mathrm{g} / \mathrm{ml}$ of streptomycin sulfate, and 10\% (v/v) FBS. Medium C was HyClone DMEM without sodium pyruvate and phenol red (SH30284.02; GE Healthcare). Medium D was medium C supplemented with 100 units/ml penicillin, $100 \mu \mathrm{g} / \mathrm{ml}$ of streptomycin sulfate, and $1 \mathrm{mM}$ sodium pyruvate (25-100-Cl; Corning). Medium E was medium D supplemented with $0.2 \%$ (w/v) BSA.

Cell culture. Stock cultures of mouse adipocytes derived from the primary stromal vascular fraction (SVF), C26c20, and MC-38 were maintained in monolayer culture at $37^{\circ} \mathrm{C}$ in $10 \%, 5 \%$, and $5 \% \mathrm{CO}_{2}$, respectively. SVF was obtained as a gift from the laboratory of Rana Gupta (UT Southwestern Medical Center). C26c20 was a gift from Kuniyasu Soda (Jichi Medical University, Shimostuke, Japan). MC-38 was obtained from the American Type Culture Collection. Each cell line was propagated, aliquoted, and stored under liquid nitrogen. Aliquots of SVF, C26c20, and MC-38 were passaged for only 3, 4, and 4 weeks, respectively, to minimize genomic instability. Every 6 months, the cell lines were tested for mycoplasma contamination using the MycoAlert Mycoplasma Detection Kit (Lonza).

Preparation of cell medium for biochemical characterization and purification. On day 0, C26c20 or MC-38 cells were set up in $100 \mathrm{ml}$ of medium B at a density of $6 \times 10^{6}$ cells/roller bottle $\left(850 \mathrm{~cm}^{2}\right.$ TufRol Roller Bottle; BD Falcon). In lieu of an incubator with constant $\mathrm{CO}_{2}$ levels, we injected roller bottles with $\mathrm{CO}_{2}$ for 15-20 seconds, at 2-5 psi, and then immediately capped each bottle. Each roller bottle was placed on a roller bottle apparatus (Wheaton) at $37^{\circ} \mathrm{C}$. On day 1 , medium was removed, and cells were washed with $100 \mathrm{ml}$ of PBS, followed by addition of $100 \mathrm{ml}$ of medium $\mathrm{D}$ with subsequent injection of $\mathrm{CO}_{2}$ before being placed back on the roller bottle apparatus at $37^{\circ} \mathrm{C}$. On day 2 , medium was collected and stored at $4^{\circ} \mathrm{C}$, followed by addition of $100 \mathrm{ml}$ of fresh medium $\mathrm{D}$ with subsequent injection of $\mathrm{CO}_{2}$ before being placed back on the roller bottle apparatus at $37^{\circ} \mathrm{C}$. On day 3 , medium was collected and stored at $4^{\circ} \mathrm{C}$. The medium collected on day 2 and day 3 were pooled and subjected to centrifugation of $100,000 \mathrm{~g}$ for 30 minutes; they were snap frozen with liquid nitrogen and stored at $-80^{\circ} \mathrm{C}$ for future use for biochemical purification and characterization of lipolysis activity.

Adipocyte lipolysis assay. SVF preadipocytes were differentiated into adipocytes as follows: On day -3 , SVF preadipocytes were set up in $1 \mathrm{ml}$ medium B at a density of $1 \times 10^{6}$ cells/well of 12 -well plates 
or $3.3 \times 10^{5}$ cells/well of 48 -well plates. On day -2 , medium was removed and replaced with fresh $1 \mathrm{ml}$ (12-well format) or $250 \mu 1$ (48-well format) of medium B. On day 0 , medium was removed, and differentiation was initiated with $1 \mathrm{ml}$ (12-well format) or $250 \mu \mathrm{l}$ (48-well format) of medium B with $0.5 \mathrm{mM}$ IBMX (MilliporeSigma), $1 \mu \mathrm{M}$ dexamethasone, and $10 \mu \mathrm{g} / \mathrm{ml}$ insulin (Cayman Chemical). On day 2, the medium was removed and replaced with fresh $1 \mathrm{ml}$ (12-well format) or $250 \mu 1$ (48-well format) of medium B with $10 \mu \mathrm{g} / \mathrm{ml}$ insulin. On day 4 and day 6 , the medium was removed and replaced with fresh $1 \mathrm{ml}$ (12-well format) or $250 \mu 1$ (48-well format) of medium B. On day 7 or 8 , medium was removed, and cells were washed twice with $1 \mathrm{ml}$ (12-well format) or $250 \mu \mathrm{l}$ (48-well format) of PBS, followed by addition of $1.5 \mathrm{ml}$ (12-well format) or $300 \mu \mathrm{l}$ (48-well format) of medium $\mathrm{E}$ with the indicated treatment. After treatment for the indicated time, 20-30 $\mu 1$ of medium from each well containing differentiated SVF adipocytes was aliquoted into 96-well plates (Thermo Fisher Scientific, catalog 12-565-501), followed by addition of $70 \mu \mathrm{l}$ of PBS and $100 \mu 1$ of free glycerol reagent. Each 96-well plate also contained a glycerol curve of a known amount of glycerol in $100 \mu \mathrm{l}$ of PBS. After 2 minutes, the amount of absorbance per well was measured using a Tecan microplate reader (absorbance $540 \mathrm{~nm}$ ). The amount of glycerol concentration released into the medium per condition over background was calculated using the measured absorbance relative to the absorbance of the standardized curve.

Partial purification of lipolysis activity from $\mathrm{C} 26 \mathrm{c} 20$ conditioned medium. All operations detailed were carried out on ice or at $4^{\circ} \mathrm{C}$, and the assay described above was used to follow triglyceride lipolysis activity through each of the 4 steps outlined in the Supplemental Table 1 purification. C26c20 medium was prepared as described above. Medium ( 1.5 1) was thawed and dialyzed against 61 of buffer A overnight, followed by centrifugation at $10,000 \mathrm{~g}$ for 15 minutes. The supernatant was collected (Supplemental Table 1, Step 1) and loaded onto a 5-ml SP-Sepharose ion-exchange column (Hi Trap SP HP, pH 7.5, GE Healthcare) preequilibrated in buffer $\mathrm{A}$. The columns were washed with 8 column volumes of buffer $\mathrm{A}$, and bound proteins were eluted with a continuous $\mathrm{NaCl}$ gradient $(0-1 \mathrm{M})$ in buffer A over 10 column volumes. Lipolysis active elution fractions were combined (Supplemental Table 1, Step 2) and concentrated from $40 \mathrm{ml}$ to $1 \mathrm{ml}$ using a 10,000 MWCO Amicon Ultra centrifugal filter that was prewashed in buffer A. The concentrated material was loaded onto gel-filtration chromatography (Tricorn 10/300 Superdex 200 column; GE Healthcare) preequilibrated with buffer B containing $100 \mathrm{mM} \mathrm{NaCl}$ (Supplemental Table 1, Step 3). The peak fractions were combined and diluted with buffer $\mathrm{B}$ to dilute $\mathrm{NaCl}$ to $\sim 25 \mathrm{mM}$. This material was subsequently loaded onto a 1-ml Q-Sepharose ion-exchange column (Hi Trap Q HP, pH 7.5, GE Healthcare) preequilibrated in buffer B. The column was washed with 10 column volumes of buffer $\mathrm{B}$, and bound proteins were eluted with a continuous $\mathrm{NaCl}$ gradient $(0-1 \mathrm{M})$. Lipolysis activity was found in the flowthrough (Supplemental Table 1, Step 4).

Immunodepletion of partially purified C26c20 medium. All operations were carried out at $4^{\circ} \mathrm{C}$ unless otherwise stated. Protein G-Sepharose beads (Santa Cruz Biotechnology Inc.) were prewashed 3 times with $500 \mu \mathrm{l}$ of PBS, with centrifugation at $960 \mathrm{~g}$ for 3 minutes between washes. Prewashed beads $(30 \mu \mathrm{l})$ were incubated with partially purified C26c20 (SP elution material, Step 2) medium for 1 hour, followed by centrifugation at $960 \mathrm{~g}$ for 3 minutes. Supernatant was removed and incubated with $2 \mu \mathrm{g}$ of the indicated antibody for 1 hour, followed by addition of $30 \mu \mathrm{l}$ of fresh prewashed Protein G-Sepharose beads. After rotation for 16 hours and centrifugation at $960 \mathrm{~g}$ for 3 minutes, the resulting supernatant was removed and used for IB analysis and adipocyte lipolysis assay.

Plasmid construction. All constructs were cloned into the pRSET B expression vector (Thermo Fisher Scientific). pLIF encoding N-terminal His6-tagged followed by a TEV protease cleavage site - and then a signal-peptide-deficient murine LIF (amino acids 24-203) — was purchased from GenScript. This construct is referred to as rLIF. Mutation of lysine to alanine at amino acid 159 of rLIF (rLIF K159A) was produced by site-directed mutagenesis of the above construct using QuikChange II XL kit (Agilent Technologies).

Purification of rLIF from E. Coli. WT and mutant plasmids were transformed into BL21 (DE3) pLysS Escherichia coli-competent cells (MilliporeSigma), followed by cell induction with $1 \mathrm{mM} \mathrm{IPTG}$ at $18^{\circ} \mathrm{C}$ for 16 hours. Hereafter, all operations were carried out at $4^{\circ} \mathrm{C}$ unless otherwise stated. A cell pellet from 61 bacterial culture was resuspended and incubated for 30 minutes in $100 \mathrm{ml}$ of buffer D containing $1 \mathrm{mg} / \mathrm{ml}$ lysozyme, $0.4 \mathrm{mg} / \mathrm{ml}$ PMSF, and protease inhibitor cocktail $(1: 1,000)$. The cells were lysed with a dounce homogenizer, followed by treatment with a tip sonicator with 3 intervals of 3 -second pulses over 3 minutes, with 10 minutes of rest on ice. This material was then subjected to centrifugation at 100,000 $\mathrm{g}$ for 60 minutes. The resulting supernatant was filtered using a $250 \mathrm{ml}, 0.2 \mu \mathrm{m}$ filter apparatus (MilliporeSigma) and subsequently loaded 
onto a 1-ml His Trap HP nickel column preequilibrated with buffer $\mathrm{C}$. The column was washed sequentially with 10 column volumes of buffer $\mathrm{C}$, followed by 10 column volumes of buffer $\mathrm{C}$ with $10 \mathrm{mM}$ imidazole. Bound protein was eluted in 5-ml fractions with buffer A containing a linear gradient of 10-500 mM imidazole. The eluted fractions were combined and concentrated to $2 \mathrm{ml}$ using a 10,000 MWCO Amicon Ultra centrifugal filter and then subjected to size-exclusion chromatography (Tricorn 10/300 Superdex 200 column; GE Healthcare) preequilibrated with buffer $C$. Protein-rich fractions were pooled and protein concentrations were quantified using a NanoDrop Instrument (Thermo Fisher Scientific). This material was incubated with purified TEV protease at a ratio of $2 \mathrm{mg}$ purified $\mathrm{rLIF}$ to $1 \mathrm{mg}$ purified His-tagged TEV protease in a final concentration of $0.2 \mathrm{mg} / \mathrm{ml}$ in buffer A overnight at $4^{\circ} \mathrm{C}$ to remove the His 6 tag on $\mathrm{rLIF}$. The cleaved material was loaded onto a 1-ml His Trap HP nickel column preequilibrated with buffer $\mathrm{C}$. The column was washed sequentially with 10 column volumes of buffer $\mathrm{A}$, followed by 10 column volumes of buffer $\mathrm{C}$ with $10 \mathrm{mM}$ imidazole. Although void of its His6 tag, rLIF still bound the nickel column and was eluted in a $2 \mathrm{ml}$ fraction with buffer $\mathrm{C}$ with $50 \mathrm{mM}$ imidazole. The eluted fractions were combined and concentrated to $2 \mathrm{ml}$ using a 10,000 MWCO Amicon Ultra centrifugal filter and then subjected to size-exclusion chromatography (Tricorn 10/300 Superdex 200 column; GE Healthcare) preequilibrated with endotoxin-free PBS. Protein-rich fractions were pooled and loaded onto a 1.5-ml Polymyxin B column (GenScript; Toxin Eraser Endotoxin Removal Kit) preequilibrated in endotoxin-free PBS, and flow-through was collected. The flow-through was reloaded onto the 1.5-ml Polymyxin B column, and this sequence was repeated a total of 10 times. The final flow-through material was brought up to a final concentration of $1 \mathrm{mg} / \mathrm{ml}$ in endotoxin-free PBS. Final purified material endotoxin levels were quantified to ensure that levels were less than $0.05 \mathrm{EU} / \mu \mathrm{g}$ purified LIF (GenScript; ToxinSensor Chromogenic LAL Endotoxin Assay Kit).

Mouse studies. Male WT Balb/c mice and C57BL/6J were obtained from Charles River Laboratories at 8 weeks of age. Male $L e p^{o b} / J(o b / o b)$ and $L e p r^{d b} / J(d b / d b)$ mice were obtained from the Jackson Laboratory at 7-8 weeks of age. All mice were allowed to acclimate in UT Southwestern animal facilities before experimentation for at least 1 week. Animals were kept in a temperature-controlled facility with a 12-hour light/ dark cycle and were fed normal chow diet and provided water ad libitum unless indicated. Approximately $100 \mathrm{~g}$ of standard chow diet (Envigo, Teklad global 16\% protein irradiated rodent diet, catalog 2916) was placed in each cage. When food reached approximately $50 \mathrm{~g}$ per cage, it was replenished to approximately $100 \mathrm{~g}$. Food was weighed at the same time daily and compared with the previous day's weight to calculate the 24-hour food intake per cage. Body weight was measured daily at the same time using a standard balance (digital Soehnle scale). Adipose tissue mass and lean tissue mass were measured longitudinally using ECHO MRI (ECHO Medical Systems) at 9 a.m. at the indicated time points. Whole blood was drawn from the tail vein, and serum was obtained by subjecting the whole blood to centrifugation at $960 \mathrm{~g}$ at $4^{\circ} \mathrm{C}$ for 10 minutes. Supernatant was removed, followed by protein concentration quantification using a bicinchonianic acid kit (Pierce), and $5 \mu \mathrm{l}$ from each condition was used in the leptin ELISA kit per manufacturer's instructions. The rest of the serum was stored at $-80^{\circ} \mathrm{C}$ for future blood analysis. At the end of the experiments, mice were euthanized using a $\mathrm{CO}_{2}$ chamber, and organs were collected and snap frozen (37).

Statistics. Data is presented as mean \pm SEM. An unpaired 2-tailed Student's $t$ test was used to determine differences between 2 groups. A Generalized Estimating Equation approach was used to determine differences between 3 or more groups over time. Significance was considered if $P<0.05$.

Study approval. All animal studies were conducted under an IACUC approved protocol at UT Southwestern Medical Center.

\section{Author contributions}

GKA, SN, AG, TG, PI, and REI designed/conducted experiments, acquired data, and analyzed data. GKA, PI, and REI wrote the manuscript. All authors reviewed the manuscript before submission.

\section{Acknowledgments}

We thank Michael Brown and Joseph Goldstein for their continued mentorship and valuable suggestions. We also thank Jay Horton, Arun Radhakrishnan, Ezra Burstein, and David Russell for their valuable suggestions. We thank Dorothy Williams, Linda Donnelly, and Niteesh Vemuri for excellent technical assistance; Ijeoma Dukes and Lisa Beatty for cell culture assistance; Joseph Sailors for assistance in interpretation of pathology slides; Alexandre Caron for help with hypothalamic processing; Chul Ahn for statistical analysis; and Andrew Lemoff and the UT Southwestern Proteomics Core for mass spectrometry analysis. 
This work was supported by grants from the NIH (T32DK007745, P30CA142543, and 5P01-HL20948) and the American Cancer Society (RSG-15-061-01-TBE and IRG-17-174-13).

Address correspondence to: Rodney E. Infante, 5323 Harry Hines Boulevard, Dallas Texas 75390-9046, USA. Phone: 214.648.6614; Email: rodney.infante@utsouthwestern.edu. Or to: Puneeth Iyengar, 2280 Inwood Road, Dallas, Texas 75235-9303, USA. Phone: 214.645.8525; Email: puneeth.iyengar@utsouthwestern.edu.

1. Solheim TS, et al. Weight loss, appetite loss and food intake in cancer patients with cancer cachexia: three peas in a pod? - analysis from a multicenter cross sectional study. Acta Oncol. 2014;53(4):539-546.

2. Tisdale MJ. Cachexia in cancer patients. Nat Rev Cancer. 2002;2(11):862-871

3. Evans WJ, et al. Cachexia: a new definition. Clin Nutr. 2008;27(6):793-799.

4. Anderson LJ, Albrecht ED, Garcia JM. Update on Management of Cancer-Related Cachexia. Curr Oncol Rep. 2017;19(1):3.

5. Zhou X, et al. Reversal of cancer cachexia and muscle wasting by ActRIIB antagonism leads to prolonged survival. Cell. 2010;142(4):531-543.

6. Agustsson T, et al. Mechanism of increased lipolysis in cancer cachexia. Cancer Res. 2007;67(11):5531-5537.

7. Rydén M, et al. Lipolysis--not inflammation, cell death, or lipogenesis--is involved in adipose tissue loss in cancer cachexia. Cancer. 2008;113(7):1695-1704.

8. Das SK, et al. Adipose triglyceride lipase contributes to cancer-associated cachexia. Science. 2011;333(6039):233-238.

9. Bischoff SC, et al. Towards a multidisciplinary approach to understand and manage obesity and related diseases. Clin Nutr. 2017;36(4):917-938.

10. Alamuddin N, Bakizada Z, Wadden TA. Management of Obesity. J Clin Oncol. 2016;34(35):4295-4305.

11. Zimmers TA, Fishel ML, Bonetto A. STAT3 in the systemic inflammation of cancer cachexia. Semin Cell Dev Biol. 2016;54:28-41.

12. Song H, Lim H. Evidence for heterodimeric association of leukemia inhibitory factor (LIF) receptor and gp130 in the mouse uterus for LIF signaling during blastocyst implantation. Reproduction. 2006;131(2):341-349.

13. Auernhammer CJ, Melmed S. Leukemia-inhibitory factor-neuroimmune modulator of endocrine function. Endocr Rev. 2000;21(3):313-345

14. Stewart CL, et al. Blastocyst implantation depends on maternal expression of leukaemia inhibitory factor. Nature. 1992;359(6390):76-79.

15. Hu W, Feng Z, Teresky AK, Levine AJ. p53 regulates maternal reproduction through LIF. Nature. 2007;450(7170):721-724.

16. Akiyama Y, et al. In vivo effect of recombinant human leukemia inhibitory factor in primates. Jpn J Cancer Res. 1997;88(6):578-583.

17. Beretta E, Dhillon H, Kalra PS, Kalra SP. Central LIF gene therapy suppresses food intake, body weight, serum leptin and insulin for extended periods. Peptides. 2002;23(5):975-984

18. Seto DN, Kandarian SC, Jackman RW. A Key Role for Leukemia Inhibitory Factor in C26 Cancer Cachexia. J Biol Chem. 2015;290(32):19976-19986.

19. Xu B, et al. Anorectic effects of the cytokine, ciliary neurotropic factor, are mediated by hypothalamic neuropeptide Y: comparison with leptin. Endocrinology. 1998;139(2):466-473.

20. Gloaguen I, et al. Ciliary neurotrophic factor corrects obesity and diabetes associated with leptin deficiency and resistance. Proc Natl Acad Sci USA. 1997;94(12):6456-6461.

21. Ettinger MP, et al. Recombinant variant of ciliary neurotrophic factor for weight loss in obese adults: a randomized, dose-ranging study. JAMA. 2003;289(14):1826-1832.

22. Miller RG, et al. A placebo-controlled trial of recombinant human ciliary neurotrophic (rhCNTF) factor in amyotrophic lateral sclerosis. rhCNTF ALS Study Group. Ann Neurol. 1996;39(2):256-260.

23. Brattain MG, Strobel-Stevens J, Fine D, Webb M, Sarrif AM. Establishment of mouse colonic carcinoma cell lines with different metastatic properties. Cancer Res. 1980;40(7):2142-2146.

24. Soda K, Kawakami M, Kashii A, Miyata M. Characterization of mice bearing subclones of colon 26 adenocarcinoma disqualifies interleukin-6 as the sole inducer of cachexia. Jpn J Cancer Res. 1994;85(11):1124-1130.

25. Fox KM, Brooks JM, Gandra SR, Markus R, Chiou CF. Estimation of Cachexia among Cancer Patients Based on Four Definitions. J Oncol. 2009;2009:693458.

26. Corbett TH, Griswold DP, Roberts BJ, Peckham JC, Schabel FM. Tumor induction relationships in development of transplantable cancers of the colon in mice for chemotherapy assays, with a note on carcinogen structure. Cancer Res. 1975;35(9):2434-2439.

27. Vaughan M, Steinberg D. EFFECT OF HORMONES ON LIPOLYSIS AND ESTERIFICATION OF FREE FATTY ACIDS DURING INCUBATION OF ADIPOSE TISSUE IN VITRO. J Lipid Res. 1963;4:193-199.

28. Hudson KR, Vernallis AB, Heath JK. Characterization of the receptor binding sites of human leukemia inhibitory factor and creation of antagonists. J Biol Chem. 1996;271(20):11971-11978.

29. Cheng JG, Chen JR, Hernandez L, Alvord WG, Stewart CL. Dual control of LIF expression and LIF receptor function regulate Stat3 activation at the onset of uterine receptivity and embryo implantation. Proc Natl Acad Sci USA. 2001;98(15):8680-8685

30. Elias CF, et al. Leptin differentially regulates NPY and POMC neurons projecting to the lateral hypothalamic area. Neuron. 1999;23(4):775-786.

31. Bates $\mathrm{SH}$, et al. STAT3 signalling is required for leptin regulation of energy balance but not reproduction. Nature. 2003;421(6925):856-859.

32. Grossberg AJ, et al. Arcuate nucleus proopiomelanocortin neurons mediate the acute anorectic actions of leukemia inhibitory factor via gp130. Endocrinology. 2010;151(2):606-616.

33. Zhang F, et al. Crystal structure of the obese protein leptin-E100. Nature. 1997;387(6629):206-209. 
34. Bahary N, Leibel RL, Joseph L, Friedman JM. Molecular mapping of the mouse db mutation. Proc Natl Acad Sci USA. 1990;87(21):8642-8646.

35. Timper K, et al. IL-6 Improves Energy and Glucose Homeostasis in Obesity via Enhanced Central IL-6 trans-Signaling. Cell Rep. 2017;19(2):267-280.

36. Komori T, Tanaka M, Senba E, Miyajima A, Morikawa Y. Deficiency of oncostatin M receptor $\beta$ (OSMR $\beta$ ) exacerbates highfat diet-induced obesity and related metabolic disorders in mice. J Biol Chem. 2014;289(20):13821-13837.

37. Caron A, et al. DEPTOR in POMC neurons affects liver metabolism but is dispensable for the regulation of energy balance. Am J Physiol Regul Integr Comp Physiol. 2016;310(11):R1322-R1331. 